\title{
Verification of Theoretically Computed Spectra for a Point Rotating in a Vertical Plane
}

D. C. Powell

J. R. Connell

R. L. George

March 1985

Prepared for the U.S. Department of Energy under Contract DE-AC06-76RLO 1830

Pacific Northwest Laboratory

Operated for the U.S. Department of Energy

by Battelle Memorial Institute 


\title{
DISCLAIMER
}

This report was prepared as an account of work sponsored by an agency of the United States Government. Neither the United States Government nor any agency thereof, nor any of their employees, makes any warranty, express or implied, or assumes any legal liability or responsibility for the accuracy, completeness, or usefulness of any information, apparatus, product, or process disclosed, or represents that its use would not infringe privately owned rights. Reference herein to any specific commercial product, process, or service by trade name, trademark, manufacturer, or otherwise, does not necessarily constitute or imply its endorsement, recommendation, or favoring by the United States Government or any agency thereof. The views and opinions of authors expressed herein do not necessarily state or reflect those of the United States Government or any agency thereof.

\author{
PACIFIC NORTHWEST LABORATORY \\ operated by \\ BATTELLE \\ for the \\ UNITED STATES DEPARTMENT OF ENERGY \\ under Contract DE-AC06-76RLO 1830
}

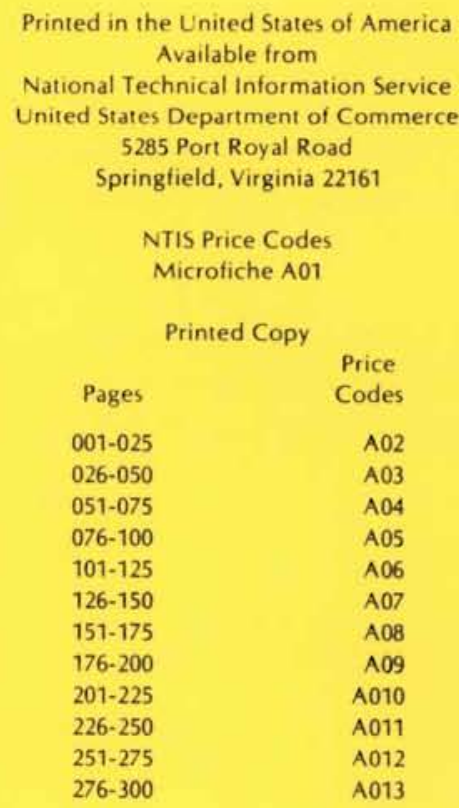


VERIFICATION OF THEORETICALLY COMPUTED SPECTRA FOR A POINT ROTATING IN A VERTICAL PLANE

David C. Powell

James R. Connell

Raymond L. George

March 1985

Prepared for the U.S. Department of Energy under Contract DE-AC06-76RLO 1830

Pacific Northwest Laboratory Richland, Washington 99352 


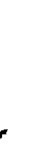


A theoretical model is modified and tested that produces the power spectrum of the alongwind component of turbulence as experienced by a point rotating in a vertical plane perpendicular to the mean wind direction. The ability to generate such a power spectrum, independent of measurement, is important in wind turbine design and testing. The radius of the circle of rotation, its height above the ground, and the rate of rotation are typical for those for a MOD-OA wind turbine.

Verification of this model is attempted by comparing two sets of variances that correspond to individual harmonic bands of spectra of turbulence in the rotational frame. One set of variances is calculated by integrating the theoretically generated rotational spectra; the other is calculated by integrating rotational spectra from real data analysis. The theoretical spectrum is generated by Fourier transformation of an autocorrelation function taken from von Karman and modified for the rotational frame. The autocorrelation is based on dimensionless parameters, each of which incorporates both atmospheric and wind turbine parameters. The real data time series are formed by sampling around the circle of anemometers of the Vertical Plane Array at the former MOD-OA site at Clayton, New Mexico.

Three time series were selected from data taken in a previous study; the time series represent slightly unstable, definitely unstable, and stable atmospheric conditions. A11 series were analyzed for 8.5-min periods of data. The first series was also analyzed for a 17-min data period.

The theoretical model verifies at a 11 frequencies from $1 P$ to $5 P$ with the 8.5-min runs except for the stable case. In all cases the ratios of variance in a harmonic band from the model to the corresponding variance from real data analysis decrease as the harmonic number increases. Since both sets of variances show decreasing magnitude with increasing harmonic number (from $1 P$, $2 P, \ldots 5 P)$, variances from the model show a more rapid decrease of energy with harmonic than do the variances from real data analysis. For the slightly unstable case these ratios ran from 1.38 at $1 P$ to 0.83 at $5 P$. However, the 
decrease of this ratio with frequency could result from noise in the observed data as well as from known and unknown limitations of the theoretical model.

The necessary input parameters for the model include the variance as well as both the longitudinal and lateral length scales of u-component turbulence. (The empirical specification of two length scales departs from the theoretical specification of a single length scale.) Evaluating these from real data analysis involves recognition that stationarity may not have existed. If the data are nonstationary, the measured variance and length scales may be larger. Therefore, the validity of the comparison of results based on specific magnitudes of these parameters is debatable, and sensitivity to a range of parameter magnitudes should be explored. Fortunately, band variances found from different sensitivity tests were within a factor of two of observed results. It was found that sensitivity to the lateral length scale is greater than sensitivity to the longitudinal length scale. It was also found that the effects of increasing variance and increasing length scales are roughly compensating but not exactly so, particularly in low frequencies. Therefore, the sensitivity of the model to an increase of these parameters caused by nonstationarity is much less than would be the case if the model sensitivity to concomitant changes were not compensating.

The spectrum of the shear of the mean wind is also modeled at the IP harmonic at all stabilities and at the $2 p$ harmonic for the slightly unstable and definitely unstable cases. The shear at higher harmonics is negligible.

The model is economical to operate, requiring typically about 4 min running time on the VAX 11/780 computer. 
CONTENTS

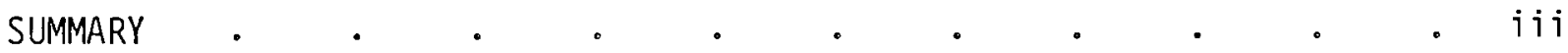

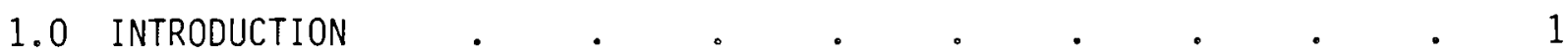

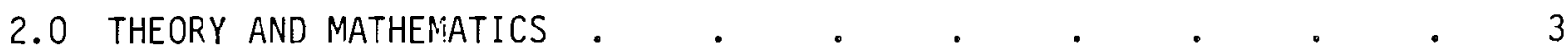

3.0 COMPUTER PROGRAMMING OF THE CORRELATION AND SPECTRAL FUNCTIONS • 7

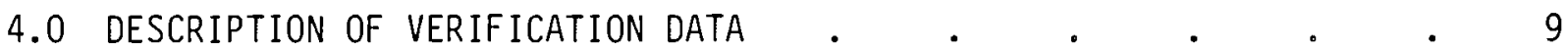

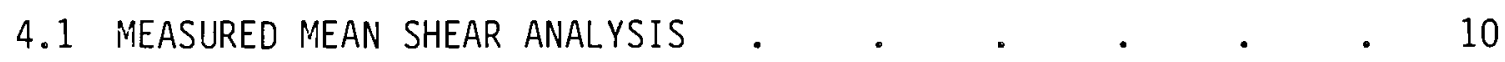

4.1.1 Assessment of the Accuracy of the Measured Mean. Wind Speeds for the Purpose of Rotational
Analysis

4.1.2 Assessment of the Prevailing Stability . . . 10

4.1.3 Assessment of Accuracy of Measured Eulerian Variances for Purposes of Rotational Sampling . $\quad . \quad 15$

4.1.4 Adopted Values of Mean Wind Speed and Variance
at Hub Height

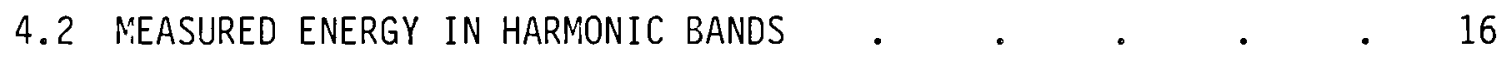

4.3 COMPARISON OF EULERIAN SPECTRUM WITH MODEL • $\quad . \quad$ • 17

5.0 VERIFICATION RESULTS - TURBULENCE WITHOUT MEAN SHEAR • • • • 19

5.1 VERIFICATION WITH OBSERVED VARIANCE AND LENGTH SCALES • • 19

5.1 .1 Adoption of Length Scale Values $\quad . \quad$. $\quad$. 19

5.1.2 Variances in the Harmonic Bands and . . . . . 20
Spectra

5.2 VERIFICATION AND SENSITIVITY STUDY USING CALCULATED

AND ARBITRARY VARIANCES AND LENGTH SCALES • • • • • $\quad$ • 24

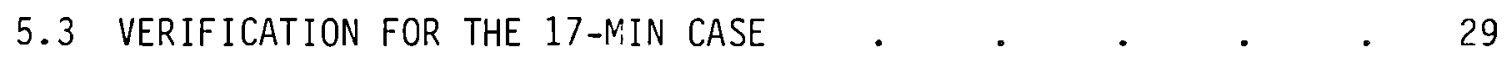

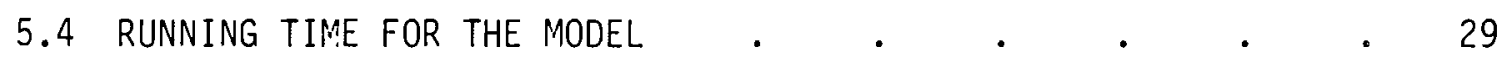

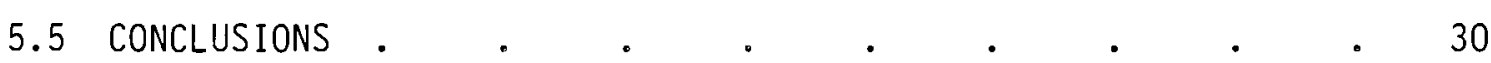




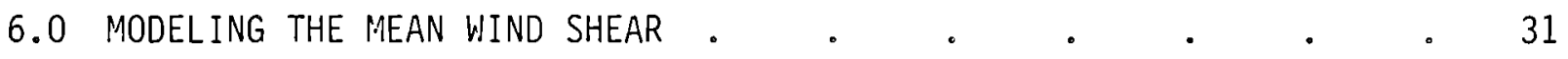

6.1 SPECTRAL ANALYSIS OF THE MODELED PROFILES . . . . 31

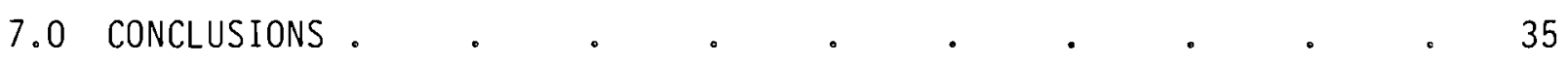

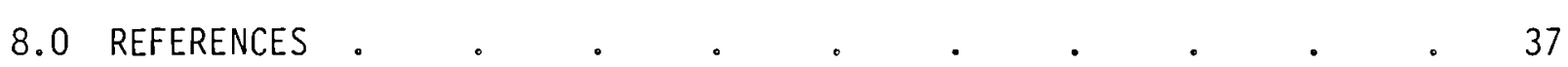

APPENDIX - RELATIONSHIP OF ROTATIONAL TO EULERIAN SPECTRA - . A-1 


\section{FIGURES}

2.1 Geometry of $r$ in Equation (2.2) $\quad . \quad$. $\quad . \quad$. $\quad . \quad 4$

4.1 Modeled and Measured Wind Speeds for Test $1 \quad$. $\quad . \quad$. 14

4.2 Modeled and Measured Wind Speeds for Test 2 and Test $3 . \quad$. 14

4.3 Eulerian Spectra for Test 1; 17-min Analysis . . . . 18

5.1 Measured and Modeled Variances for Five Harmonics . . 21

5.2 Rotationally Sampled Spectra . . . . . . . . . 22

5.3 Rotationally Sampled Spectra for Test 1 . . . . 23

5.4 Measured and Modeled Variances for Five Harmonics Using

5.5 Rotationally Sampled Spectra for Four Length Scale Scenarios • 25

5.6 Comparison of Rotational Spectra for Two Length Scale
Scenarios

5.7 Comparison of lieasured and Modeled Variances for Five
Harmonics, Test 1, 17 min $. \quad . \quad . \quad$.

6.1 Rotationally Sampled Spectrum Produced by the Model . . 33

A.1 Comparison of "Rotational Spectrum" at Zero Rotation
Rate with von Karman Variant Spectrum $\quad . \quad \ldots \quad . \quad A-3$

A.2 Comparison of von Karman Spectrum and Variant Spectrum . . . . . . . . . A-4

A.3 Comparison of Kaimal u Spectrum and the von Karman
Variant . . . . . . . A-5 


\section{$\underline{\text { TABLES }}$}

4.1 Measured Mean Wind Speeds, Test 1 . $\quad . \quad$. $\quad . \quad 10$

4.2 Measured and Modeled Mean Wind Speed Profiles, Test 1, Assuming Neutral Stability. $\quad$. $\quad . \quad$. $\quad . \quad 12$

4.3 Measured Eulerian Variances, Test $1.0 . \quad . \quad . \quad . \quad$. 15

4.4 Average Eulerian Variances at Different Height. . . . . 16

4.5 Hub-Height Mean Wind Speed and Eulerian Variance Values

4.6 Measured Variances in the Harmonic Bands, Test $1 . \quad . \quad 017$

4.7 Measured Variances in the Harmonic Bands, Tests 2 and 3. . . 17

6.1 Variance in the Shear Contribution to the Measured Harmonic Band. . . . . . . . . 31

6.2 Corresponding Analysis Using Time Series Derived from

6.3 Ratios Between Modeled and Measured Values in the 


\subsection{INTRODUCTION}

Spectral analysis of turbulence sampled at a rotating point, such as a point near the tip of a wind turbine blade, has been shown to be relevant to the spectra of stresses on rotating wind turbine blades (Connell and George 1983). Techniques have been devised to calculate spectra in the rotating frame of reference using data from 12 positions on a circle at the Vertical Plane Array (VPA) at Clayton, New Mexico. Spectra so calculated have been compared to the spectra of bending moments, with favorable result, by Connell and George (1983).

It would be desirable to demonstrate that the rotational spectrum (Connell 1981) that applies at a point on a wind turbine blade, under specified conditions of mean wind speed, stability, and surface roughness, can be calculated by formula, at least as well as can be done for the Eulerian, or non-moving point, spectrum. This should hold for the normal, radial and tangential components of wind relative to the disk of rotatation. (Only the normal component is addressed in this report.)

In one respect modeling of the rotational spectrum should be easier than modeling the Eulerian spectrum. This is because interest is chiefly in the frequency band beginning at half the rotational frequency of the blade and extending upward into the upper harmonic frequencies. Therefore, modeling of energy content at low frequencies, regarding which uncertainty is considerable, is less critical. However, some concern in the low frequency modeling still remains because part of the energy at low frequencies is translated up into the rotational frequencies by the rotational process.

The purpose of this report is to compare rotational spectra computed with a theoretical model with spectra calculated from real data from the Clayton VPA, which have been formed into rotational sequence. Three samples of such data are chosen, taken under contrasting conditions of atmospheric stability. Because the model that produces the rotational spectrum has no diabatic terms (i.e., terms parameterizing the stable or the unstable atmosphere, as opposed to the neutral atmosphere), the analysis is weighted principally on the test during which atmospheric stability departed least from neutrality. 
This report is organized as follows: Section 2 restates and slightly modifies the theory used in the rotational spectrum model. This spectrum applies to the wind component normal to the disc of rotation. Section 3 describes the analytical features of the computer program that makes the model calculations. Section 4 describes and qualifies the Clayton VPA data from which the measured rotational spectra were calcualted.

The VPA data were analyzed in two modes. First, rotational spectra were calculated using the full rotational data. Second, the mean wind speed at.each anemometer was removed, thus removing the effect of mean wind shear. Spectra were then calculated for these rotational data, containing only the turbulence effect. The theoretical model for the rotational spectrum models the turbulence only. The verification results for the turbulence-only rotational spectrum are given in Section 5. The spectrum of the shear of the mean wind, as observed and as calculated using boundary-layer profile theory, is evaluated in Section 6 . 


\subsection{THEORY AND MATHEMATICS}

The basic statistical theory for turbulence as experienced by a point moving in a vertical plane perpendicular to the mean wind direction in the wind turbine 1ayer is given by (Conne11 1981). The autocorrelation function of u-component turbulence in the path of the rotating point is given by

$$
R_{11}=\frac{2}{\Gamma(1 / 3)} \sigma^{2}\left(\frac{r}{2 L}\right)^{1 / 3}\left\{K_{1 / 3}\left(\frac{r}{L}\right)-\frac{r}{2 L}\left[1-\frac{x^{2}}{r^{2}}\right] K_{2 / 3}\left(\frac{r}{L}\right)\right\} .
$$

where:

$\Gamma$ is the gamma function

$\sigma^{2}$ is the turbulence variance

$r$ is the separation distance

$L$ is a length characteristic of the turbulence

$\mathrm{K}_{1 / 3}$ is the modified Bessel function of the second kind of fractional order $1 / 3$

$x$ is the alongwind component of the separation distance.

To physically understand the $r$ one must visualize the two ends of the segment defining $r$ as follows. The one end is fixed to an arbitrary point on the blade and thus describes a circular path in the disc of rotation, perpendicular to the mean wind direction, as the blade rotates. The other end is downstream of its original position on the blade at a distance $x$, or $U$ t where $U$ is mean wind speed and $t$ is travel time. Mathematically this is expressed by (see Conne 11 1981)

$$
r^{2}=\left[2 \rho \sin \left(\frac{\Omega t}{2}\right)\right]^{2}+(U t)^{2}
$$

where $\rho$ is the radius of rotation of the one end and $\Omega$ is the rotation rate. The two terms express the rotational and translational effects, respectively (see Figure 2.1). Obviously the second term dominates the first as $t$ becomes large. 


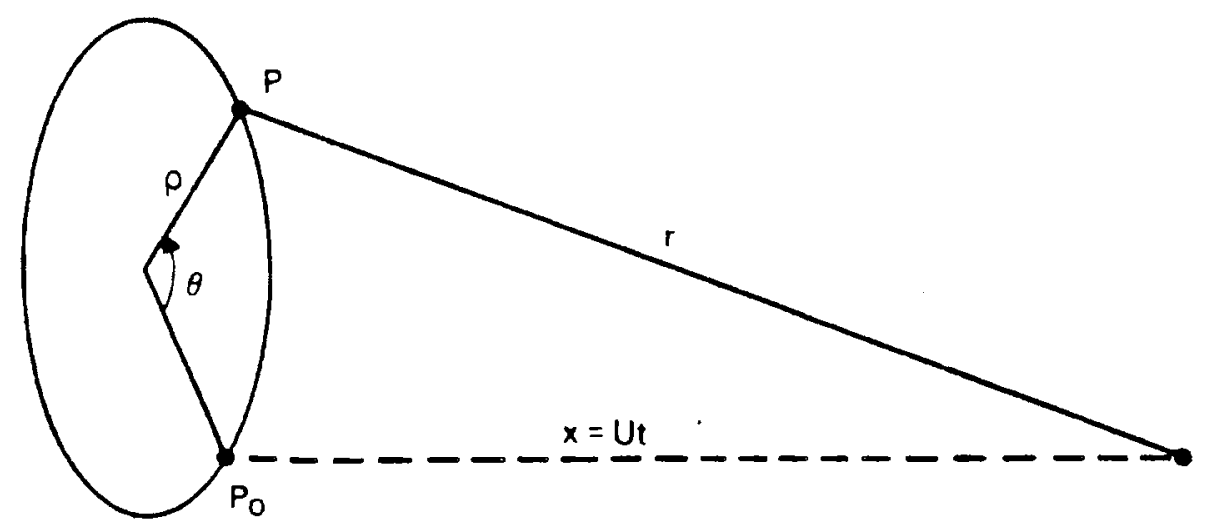

$P_{0}$ is position of $P$ at initial time.

$\Omega \mathrm{t}=\theta+2 \mathrm{n} \pi$ where $\mathrm{n}$ is number of revolutions in time $\mathrm{t}$.

FIGURE 2.1. Geometry of $r$ in Equation (2.2)

The development of a theoretical model of rotational spectra is facilitated by defining the following dimensionless variables. The first two relate turbulence and machine properties; the last is time related to the blade rotation rate:

$$
\begin{aligned}
& \alpha=\rho / L_{a} \\
& \beta=U / \Omega L_{b} \\
& \bar{\tau}=\Omega \tau / 2 .
\end{aligned}
$$

$L_{a}$ and $L_{b}$ are two length scales, in place of the one in Equation (2.1). This is actually a modification of the theory of Equation (2.1), motivated by the fact that the length scale in $\alpha$ is associated with the radius, which extends in all lateral directions, while the length scale in $\beta$ is associated with the longitudinal mean wind speed. Thus it is hypothesized that more than one length scale may be physically relevant. 
$L_{b}$ is the usual length scale of turbulence. Theoretically, it is the product of the mean wind speed and the infinite integral of the autocorrelation function,

$$
L_{b}=\left(L_{u}\right)_{x}=U \int_{0}^{\infty} \rho(\tau) d(\tau) .
$$

This presumes that the following limit exists:

$$
\operatorname{Lim}_{T \rightarrow \infty} \int_{0}^{T} \rho(\tau) d(\tau) .
$$

Alpha $(\alpha)$ is a radial distance from the center of rotation divided by the turbulence length scale, $L_{a} . U$ is the mean wind speed. $\Omega$ is blade rotation in radians per second. $\beta$ is the period of rotation $2 \pi / \Omega$ made dimensionless by multiplying by $U / 2 \pi L_{b} . \bar{\tau}$ is the correlation time made dimensionless by multiplying by half the rotation frequency in radians.

We note that

$$
x / L_{b}=2 B \bar{\tau} .
$$

We define the autocorrelation function

$$
\rho(\bar{\tau})=R_{11} / \sigma^{2}
$$

Substitution of Equations (2.2), (2.3), and (2.4) into (2.1) and then into (2.9) yields:

$$
\rho(\bar{\tau})=[2 / \Gamma(1 / 3)]\left(\alpha^{2} \sin ^{2} \bar{\tau}+\beta^{2} \bar{\tau}^{2}\right)^{1 / 6}(A-B)
$$




$$
A=K_{1 / 3}\left[2\left(\alpha^{2} \sin ^{2} \bar{\tau}+B^{2} \bar{\tau} 2\right) 1 / 2\right]
$$

where

$$
B=\frac{\left(\alpha^{2} \sin ^{2} \bar{\tau}\right)}{\left(\alpha^{2} \sin ^{2} \bar{\tau}+\bar{\tau}^{2} \beta^{2}\right)^{1 / 2}} K_{2 / 3}\left[2\left(\alpha^{2} \sin ^{2} \bar{\tau}+\beta^{2} \bar{\tau}^{2}\right) 1 / 2\right]
$$

The function $\rho(\bar{\tau})$ is a correlation of the dimensionless time variable $\bar{\tau}$ in terms of the dimensionless parameters $\alpha$ and $\beta$.

The power spectrum is the Fourier transform of the autocorrelation function. Since we want the spectrum with a dimensional frequency argument, we use the autocorrection function of dimensional time,

$$
\rho(t)=\rho(\bar{\tau}), \quad \bar{\tau}=2 \tau / \Omega,
$$

and write the spectral transform as follows:

$$
S(n)=4 \sigma^{2} \int_{0}^{\infty} \rho(t) \cos (2 \pi n t) d t
$$

where

$$
\sigma^{2}=\int_{0}^{\infty} S(n) d n .
$$

In the rest of this section we use the logarithmic form of the spectrum, which is the principal form encountered in the meteorological literature. This is $n S(n)$, which integrates to yield the variance according to

$$
\sigma^{2}=\int_{0}^{\infty} n S(n) d[\ln (n)] .
$$

The programming for the VAX $11 / 780$ computer required to generate the rotational spectra according to Equations (2.1) through (2.10) involved significant problems not explicit in those equations. Therefore, the programming is described in some detail in the following section. 


\subsection{COMPUTER PROGRAMMING OF THE CORRELATION AND SPECTRAL FUNCTIONS}

A computer program has been written that reads in a list of turbulence and wind turbine parameter values and then calculates the correlation and spectral functions for a point rotating in a vertical plane perpendicular to the mean wind direction in the homogeneous isotropic turbulence. One Eulerian spectrum by Kaimal and one following von Karman are also computed for comparison. These spectra are given in Equations (A.3) and (A.4) in the Appendix.

The program first reads in a required set of Eulerian and rotational parameters:

- Eulerian parameters (required)

$Z$ - hub height

$U$ - mean wind speed at height $z$

$z_{0}$ - surface roughness length

- rotational parameters

ENO - rotation rate

$\mathrm{R}$ - rotation radius.

Other parameters handled optionally by read statements or by calculation in the code are $\sigma_{u}$ and the two length scales $L_{a}$ and $L_{b}$.

The program reads two other input parameters that govern the length and time step of the autocorrelation function:

- KMAX - the upper bound for the number of values to be calculated for the autocorrelation function

- TFAC - ratio of the time interval in the correlation function to half the reciprocal of the Nyquist frequency of the calculated spectrum.

KMAX prevents the program from calculating and storing more than a given number of values in the autocorrelation vector. If KMAX is too low, the truncated autocorrelation function may be transformed into a spectrum with negative values. If there is no restriction (KMAX very large), the program may store correlation values beyond the dimensioned capacity.

Intuitively one would assume that the product of the time interval of the correlation function and Nyquist frequency should be one-half. Therefore, TFAC 
has a trivial value of one. If this is done, the spectrum is badly aliased on the high frequency end. Making TFAC smaller reduces aliasing and also increases the cost by requiring more values in the correlation function. The value 0.25 was considered optimum.

The required value of KMAX depends on the value of TFAC used. The adopted value of KMAX was 12000 .

The program calculates the dimensionless parameters $\alpha$ and $\beta$ and then calculates the correlation function from Equation (2.10). Next the following spectra for the u component are computed:

$$
\begin{aligned}
& n S(n) \text { - rotational } \\
& S(n) \text { - rotational } \\
& n S(n) \text { - Eulerian Kaimal } \\
& S(n) \text { - Eulerian Kaimal } \\
& n S(n) \text { - Eulerian von Karman. }
\end{aligned}
$$

The $n S(n)$ spectra are computed at frequencies that are evenly spaced on a logarithmic scale, at 40 per frequency decade. Thus the ratio of successive frequencies for $n S(n)$ is $10^{0.025}$. The $S(n)$ spectra are computed at evenly spaced frequencies, the difference between successive frequencies being one-tenth oi the rotation rate. The rotation rate is called $1 P$ and is the tenth frequency at which $S(n)$ is calculated.

In order to calculate $n S(n)$ at the exact harmonic frequencies of the blade rotation rate, it is necessary to $f$ ind the nearest frequency in the set to each harmonic (1P, 2P...NP) and arbitrarily alter the frequency to match the harmonic. This is a small change made by multiplying or dividing the original value of $n$ by a number not exceeding 100.0125, which is 1.0292 . If this is not done, a plot of an $n S(n)$ spectrum may show obvious chopping off at the tops of some of the harmonic spikes.

This section concludes the theoreticai and mathematical background of the report. In the succeeding sections the results of data analysis are given. 


\subsection{DESCRIPTION OF VERIFICATION DATA}

The description of the verification data must first of all include the fitness of the data for the intended verification exercise. The sensitivity of the verification results to deficiencies in the data depends on the particular parameters used in the verification. These are of two types: rotational spectra, finely resolved in frequency; and the variances calculated by integrating these spectra across individual frequency bands surrounding the harmonic spikes at frequencies $1 P, 2 P \ldots .5 P$. The energy expressed in these variances is the second parameter sought.

The data analyzed to produce the verification spectra and variances were taken with the VPA of fixed-propeller anemometers at Clayton, New Mexico. Results obtained from analysis of these data have been reported by Connell and George (1983).

The geometry of the VPA is that of a circle in the vertical plane that should be normal to the mean wind direction. The center of the circle is $30.5 \mathrm{~m}$ above surface, and the radius is $19 \mathrm{~m}$.

According to Connell and George (1983), the data composing the neutra?, stable, and unstable cases were taken as follows:

$$
\begin{aligned}
& \text { Test 1: 11/25/81 starting 11:49 } \\
& \text { Test 2: 12/18/81 starting 16:11 } \\
& \text { Test 3: 3/22/82 starting 09:22 }
\end{aligned}
$$

where Test 1, Test 2, and Test 3 refer to the cases called, for simplicity, neutral, stable, and unstable, respectively. All three have 512 samples at one sample per second.

These data are available as portions of longer segments. In order to avoid making the verification results dependent upon the sample length of data chosen, Test 1 was also analyzed as a 17-min segment. 


\subsection{I:EASURED MEAN SHEAR ANALYSIS}

\subsubsection{Assessment of the Accuracy of the Measured Mean Wind Speeds for the Purpose of Rotational Analysis}

The mean wind speeds measured from the VPA for Test 1 are given in Table 4.1.

\section{TABLE 4.1. Measured Mean Wind Speeds, Test 1}

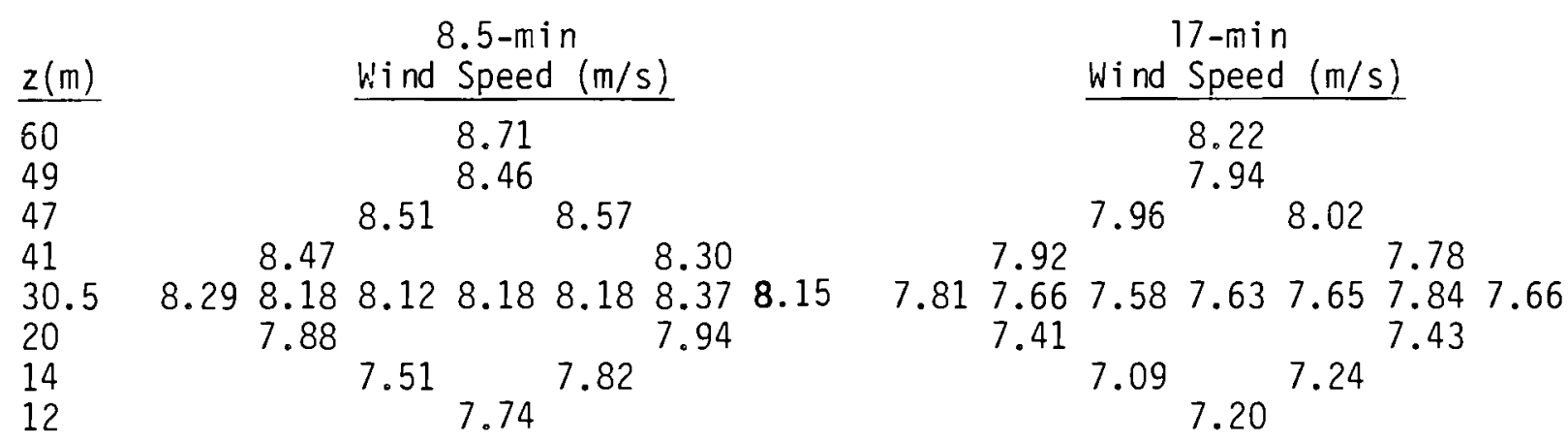

These mean values have several features that appear to be imperfect. One notices differences between two readings at the same level; for example, there is a difference of $0.31 \mathrm{~m} / \mathrm{s}$ at the $14-\mathrm{m}$ level in the 8.5-min analysis. This difference drops to $0.15 \mathrm{~m} / \mathrm{s}$ in the $17-\mathrm{min}$ analysis. Therefore, the differences between anemometers at the same level are not the same for the 8.5-min analysis as they are for the 17-min analysis. An unexpected feature is that the average values at the $47-m$ level are less than the value measured at $49 \mathrm{~m}$.

In summary, there appears to be unevenness in the measured profile that is not characteristic of the steady atmosphere over uniform terrain. As a result, spectral analysis of data in the rotational frame, including mean wind speeds, will have some content in the harmonic bands that is probably not of atmospheric origin.

\subsubsection{Assessment of the Prevailing Stability}

One method of assessing meteorological stability is to examine the variation of the mean wind with height, $U(z)$. Values of $U(z)$ averaged over several minutes at several heights may be represented by a continuous function of $z$ that is called a profile. The profile should ordinarily be a monotonic increasing 
function of height. The increase of wind with height $\mathrm{dU} / \mathrm{dz}$ (called the shear) depends on both surface roughness and stability.

Therefore, errors can be made in estimating stability from the profile if the surface roughness has been inaccurately estimated. This estimation may be made roughly using tables based on surface cover such as those given by Counihan (1975). However, refined estimation of surface roughness length for a particular site must be made only from wind profiles that are assumed to be representative of neutral stability.

Stability estimation for data taken at a particular site requires assuming a surface roughness value $z_{0}$ for that site and examining estimates for many samples taken under known conditions. If no bias is apparent, when analytically estimated stability is compared to stability estimated by rough human observation, the assumed surface roughness length may be assumed correct.

The surface roughness that applies at clayton varies, as it does at many other sites, with wind direction because the topography is of different roughness at different directions from the tower. The ciata analyzed in this report were all taken when the wind direction was in that of least roughness, for which a value of $0.005 \mathrm{~m}$ has been estimated (see Chan et al. 1983).

All this discussion should warn the reader that stability estimation using wind shears at the typical wind turbine site is necessarily gross. The final assessment of the stability for the three tests is

$$
\begin{aligned}
& \text { Test } 1 \text { - slightly unstable } \\
& \text { Test } 2 \text { - definitely stable } \\
& \text { Test } 3 \text { - definitely unstable. }
\end{aligned}
$$

The formula for calculating the mean wind speed at one level from that at another level, assuming neutral stability, is

$$
U\left(z_{2}\right)=U\left(z_{1}\right) \ln \left(z_{2} / z_{0}\right) / 1 n\left(z_{1} / z_{0}\right)
$$


Here $z_{1}$ is a reference level that should be in the surface boundary layer, which includes $30.5 \mathrm{~m}$, the central height of the rotational disc used for $z_{1}$ in this report. Comparison of $U\left(z_{2}\right)$ calculated from Equation (4.1) may be made with the measured profile. If the measured profile has more shear than that calculated, a stable atmosphere is assumed. Conversely, if the measured profile has less shear than that calculated, an unstable atmosphere is assumed. The average wind speeds at the $30.5-\mathrm{m}$ level for the two periods are 8.21 and $7.69 \mathrm{~m} / \mathrm{s}$, respectively. The average values at each height of measured values and values calculated using $0.005 \mathrm{~m}$ for the value of $z_{0}$ are given in Table 4.2.

TABLE 4.2. Measured and Modeled Mean Wind Speed Profiles, Test 1, Assuming Neutral Stability

\begin{tabular}{|c|c|c|c|c|}
\hline \multirow[b]{2}{*}{$\underline{z(m)}$} & \multicolumn{2}{|c|}{$\begin{array}{c}8.5-\mathrm{min} \\
\text { Wind Speed }(\mathrm{m} / \mathrm{s})\end{array}$} & \multicolumn{2}{|c|}{$\begin{array}{l}\text { 17-min } \\
\text { Wind Speed }(\mathrm{m} / \mathrm{s})\end{array}$} \\
\hline & Log Law & Average Measured & Log Law & Average Measured \\
\hline 60 & 8.85 & 8.71 & 8.29 & 8.22 \\
\hline 49 & 8.66 & 8.46 & 8.11 & 7.94 \\
\hline 47 & 8.62 & 8.54 & 8.07 & 7.99 \\
\hline 41 & 8.49 & 8.39 & 7.95 & 7.85 \\
\hline 30.5 & 8.21 & 8.21 & 7.69 & 7.69 \\
\hline 20 & 7.81 & 7.91 & 7.32 & 7.42 \\
\hline 14 & 7.48 & 7.66 & 7.00 & 7.17 \\
\hline 12 & 7.33 & 7.74 & 6.87 & 7.20 \\
\hline
\end{tabular}

In spite of the distortion in the measured shear profile, it is evident that this iog-law model predicts too much shear. Less shear will be predicted if either a lower value of $z_{0}$ is assumed, or if the atmosphere is assumed to be unstable. Corroborating evidence for the latter assumption will be presented later in the Eulerian variance analysis.

To assess the degree of instability, it is necessary to estimate a value for the Monin-Obukhov stability length, (-L; see Businger et al. 1971). For the unstable atmosphere $-L$ is conventionally positive and approaches infinity as the instability approaches neutrality. Representative values are 10 to $30 \mathrm{~m}$ under the afternoon sun. Because Test 1 was thought to have taken place under neutrai conditions, we estimate a larger value for $-L$, namely $100 \mathrm{~m}$, and use it in the version of Equation (4.1) for the unstable atmosphere (see Paulson 1970). This equation is: 


$$
U\left(z_{2}\right)=U\left(z_{1}\right) \frac{\ln \left(z_{2} / z_{0}\right)-\psi\left(x_{2}\right)}{\ln \left(z_{1} / z_{0}\right)-\psi\left(x_{1}\right)}
$$

where

$$
\begin{gathered}
\Psi(x)=2 \ln \frac{1+x}{2}+\ln \frac{1+x^{2}}{2}-2 \tan ^{-1} x+\pi / 2 \\
x=(1-15 \mathrm{z} / L)^{1 / 4} .
\end{gathered}
$$

Note that $x=1$ when $-L$ is infinite (neutral atmosphere) and $\psi=0$.

To assess the stability of Test 3 , the log-linear law for stable conditions is needed. This is given by (see Dyer 1974).

$$
U\left(z_{2}\right)=U\left(z_{1}\right) \frac{\ln \left(z_{2} / z_{0}\right)+5 z_{2} / L}{\ln \left(z_{1} / z_{0}\right)+5 z_{1} / L}
$$

Note that $+\mathrm{L}$ is used to model the stable case.

For the slightly unstable case, the profiles of wind speed measured and wind speed modeled after Equation (4.2) are shown in Figure 4.1. Since the model fits well at all except the highest and lowest anemometers, the $-L$ value of $100 \mathrm{~m}$ is assumed appropriate, and the mean wind speed readings are assumed correct except at the highest and lowest anemometers, where they appear to be slightly high.

In a similar way, the stabilities prevailing at the time of Test 2 and Test 3 were assessed. These turned out to be definitely stable and unstable, agreeing with previous description. The measured and modeled profiles are shown in Figure 4.2 .

The modeled wind profiles obviously disagree with the measured profiles in curvature at certain heights. However, the curvature cannot be changed without changing also the mean slope, which appears to be reasonably good for the unstable case, in general, and also for the upper half of the rotational disc in the stable case. Therefore, we assume that the definitely stable character prevailed during Test 2 and that the definitely unstable character prevailed 


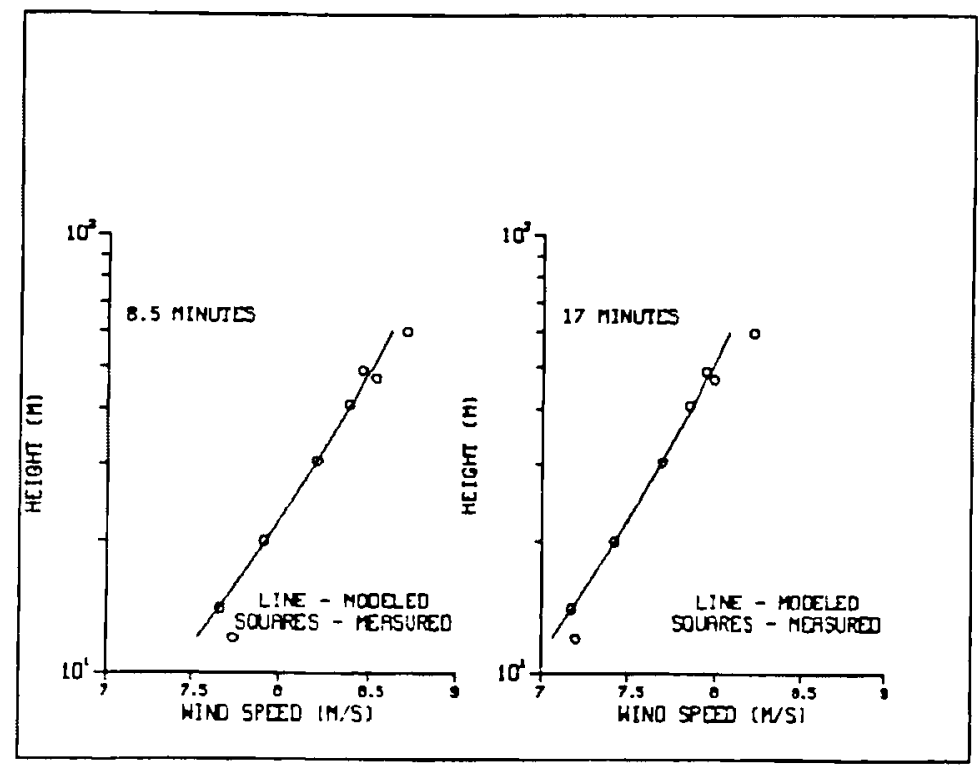

FIGURE 4.1. Modeled and Measured Wind Speeds for Test 1

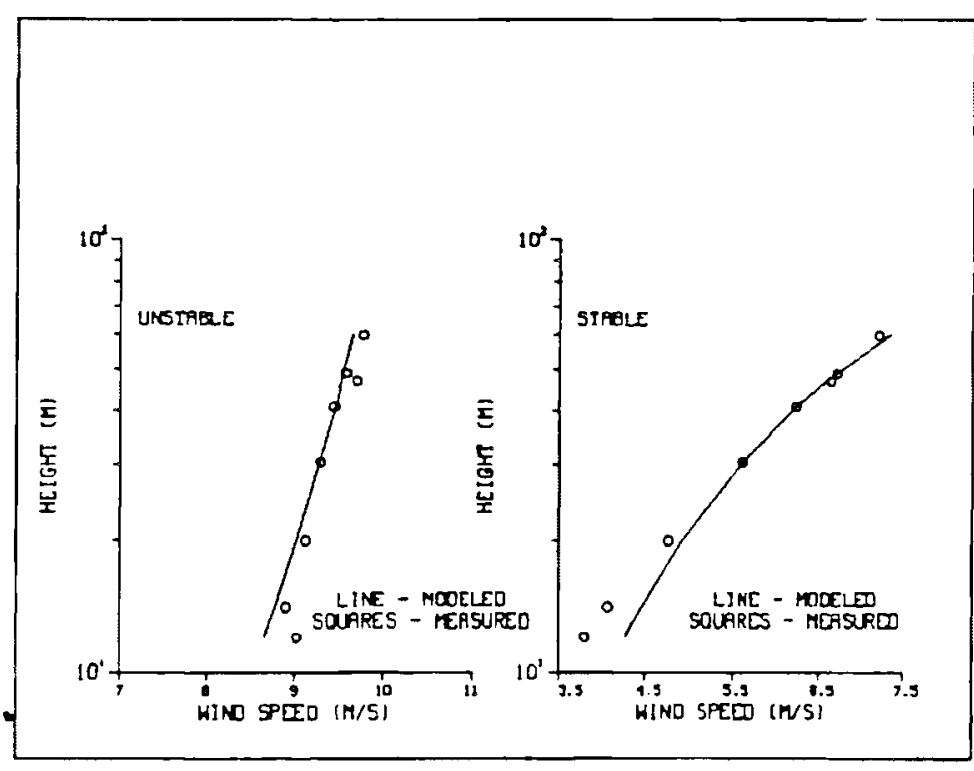

FIGURE 4.2. Modeled and Measured Wind Speeds for Test 2 and Test 3. 
during Test 3 . Estimated $L$ values used in modeling these profiles were $+35 \mathrm{~m}$ and $-25 \mathrm{~m}$, respectively.

\subsubsection{Assessment of Accuracy of Measured Eulerian Variances for Purposes of Rotational Sampling}

The Eulerian variances from the Test 1 analysis are as follows given in Table 4.3.

TABLE 4.3. Measured Eulerian Variances, Test 1

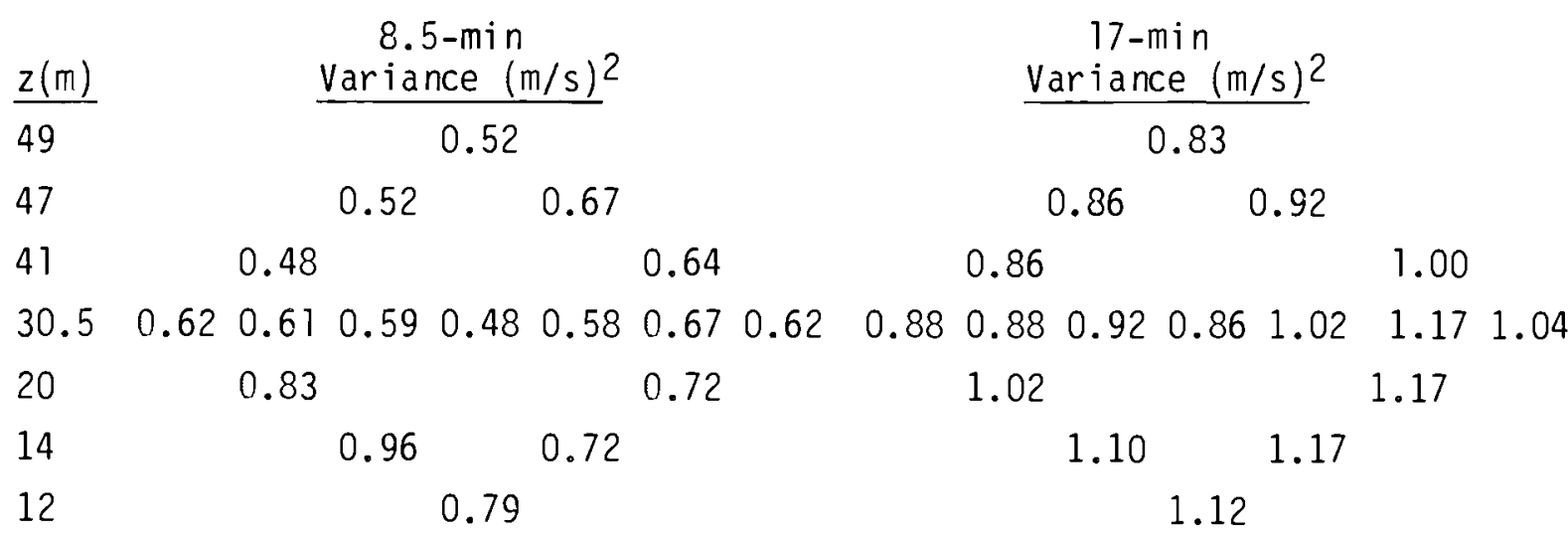

These variances obviously differ at the same level but not in the same way that the mean wind speeds differ at the same level. The difference is that the higher mean wind speed value of two recorded at the same level is at the same anemometer in both the 8.5- and 17-minute segments, while this is not so in the Eulerian variance analysis. This is shown below in Table 4.4, where the letters $E$ and $W$ indicate that the higher variance was recorded on the east or the west anemometer. Below $30.5 \mathrm{~m}$, this pattern reverses.

From the above we shall assume that the variances are not distorted by problems peculiar to the individual anemometers. There are two reasons:

1. The ratios in Table 4.4 decrease when the 17 -min analys is is compared with the 8.5-min analysis.

2. The greater variance of two at the same level may change sides when the 8.5-min result is compared with the $17-\mathrm{min}$ result. This is hard to explain as an instrumental aberration. 
TABLE 4.4. Average Eulerian Variances at Different Heights

\begin{tabular}{|c|c|c|c|c|}
\hline \multirow[b]{2}{*}{$z(m)$} & \multicolumn{2}{|r|}{$8.5 \mathrm{~min}$} & \multicolumn{2}{|r|}{17 min } \\
\hline & Avg. & $\begin{array}{l}\text { Ratio at } \\
\text { Same Height (a) }\end{array}$ & Avg. & $\begin{array}{c}\text { Ratio at } \\
\text { Same Height (a) }\end{array}$ \\
\hline $\begin{array}{l}49 \\
47 \\
41 \\
30.5 \\
20 \\
14 \\
12\end{array}$ & $\begin{array}{l}0.52 \\
0.59 \\
0.56 \\
0.62 \\
0.77 \\
0.84 \\
0.79\end{array}$ & $\begin{array}{l}1.29 \mathrm{E} \\
1.33 \mathrm{E} \\
1.00 \\
1.15 \mathrm{~W} \\
1.33 \mathrm{~W}\end{array}$ & $\begin{array}{l}0.83 \\
0.89 \\
0.93 \\
0.96 \\
1.09 \\
1.13 \\
1.12\end{array}$ & $\begin{array}{l}1.07 E \\
1.16 E \\
1.18 E \\
1.15 E \\
1.06 E\end{array}$ \\
\hline
\end{tabular}

(a) At hub height the average and the ratios are taken from the two outer
anemometers on the rotational path only. The ratios are the ratio
of the higher of the two readings to the lower, regardless of position.

4.1.4 Adopted Values of Mean Wind Speed and Variance at Hub-Height

The values given in Table 4.5 were adopted for hub-height mean wind speed and variance for the three tests.

TABLE 4.5. Hub-Height Mean Wind Speed and Eulerian Variance Values for Each Test.

\begin{tabular}{|c|c|c|c|c|}
\hline $\begin{array}{l}\text { Mean (mis) } \\
\text { Variance }\end{array}$ & $\begin{array}{l}8.21 \\
0.62\end{array}$ & $\begin{array}{l}7.69 \\
0.96\end{array}$ & $\begin{array}{l}9.28 \\
0.65\end{array}$ & $\begin{array}{l}5.64 \\
0.19\end{array}$ \\
\hline
\end{tabular}

\subsection{MEASURED ENERGY IN HARMONIC BANDS}

The principal concern of this document is the modeling of energy in the harmonic bands of the first five harmonics of the rotational frequency. Modeled versions of the kind of spectrum that was integrated to obtain these results are shown later in Figures 5.2, 5.5, and 5.6.

From the Test 1 these values given in Table 4.6 were obtained.

We note that variances in the bands are greater for the 17-min period than for the 8.5-min period although the mean wind speed was greater for the 8.5-min 
TABLE 4.6. Measured Variances in the Harmonic Bands, Test 1

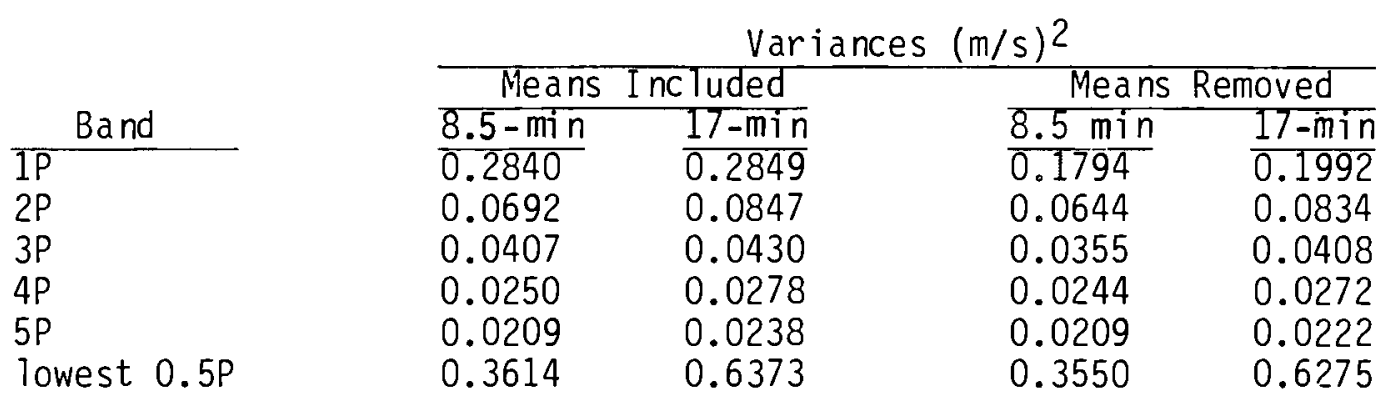

period. Also the overall variances for the 17-min period are greater than those for the 8.5-min period, but the ratios of the overall variances of the 17-min period to those of the 8.5-min period are greater than the corresponding ratios of the band variances. Thus, exact modeling of the band variances for short time segments will not be a simple task.

In a similar way we arrive at average mean wind speeds at each height and the average hub-height variance for Test 2 and Test 3 as shown in Table 4.5.

The mean wind speeds and variances with the mean shear removed are given in Table 4.7 .

TABLE 4.7. Measured Variances in the Harmonic Bands, Tests 2 and 3

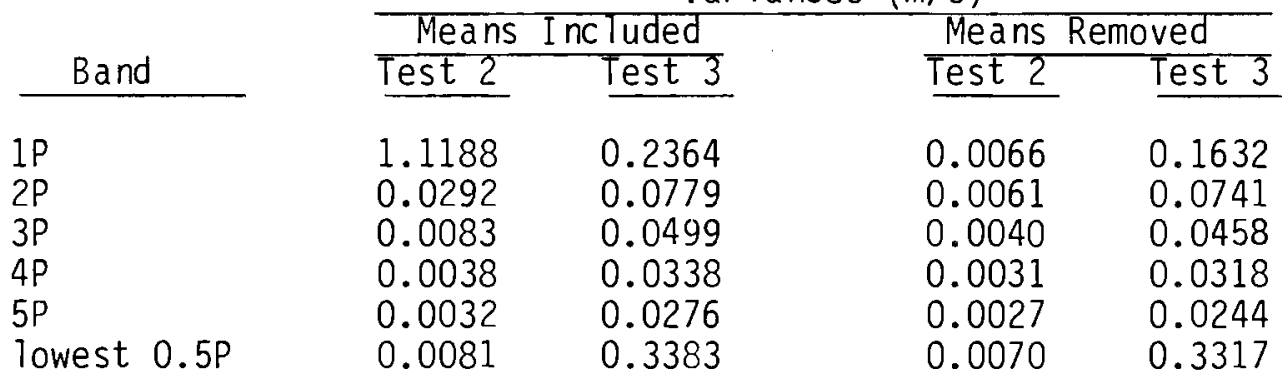

\subsection{COMPARISON OF EULERIAN SPECTRUM WITH MODEL}

The Eulerian u spectra for the two anemometers in the Test 1 17-min analysis are shown along with a Kaimal u spectrum for the neutral atmosphere (see Equation A.4) in Figure 4.3. 


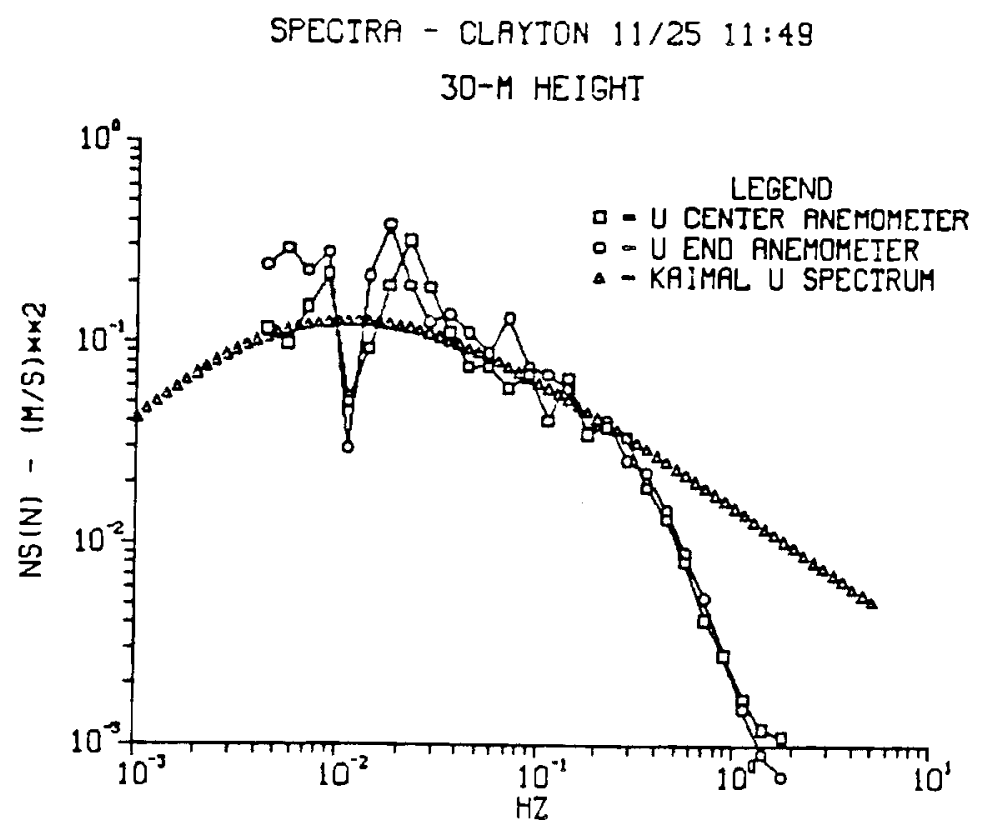

FIGURE 4.3. Eulerian Spectra for Test 1; 17-min Analysis

The spectrum for the neutral atmosphere was used rather than that for the unstable atmosphere because the former requires less parameterization and the sample spectrum is not defined back in the low-frequency domain where the difference betgween the two theoretical spectra is the greatest. The level of the Kaimal spectrum was established by computing $u_{*}$ using the logarithmic wind law (see Equation A.5).

The measured spectra show high frequency damping of anemometer responsiveness, which is expected because of the distance constant of the measurement system. The measured spectra follow only the low frequency end of the isotropic $(5 / 3$ law) region. We shall not presume to "correct" the measured Eulerian varivariances. 


\subsection{VERIFICATION RESULTS - TURBULENCE WITHOUT MEAN SHEAR}

Verification depends upon obtaining three sets of harmonic variances that match those given for the three cases, called Test 1, Test 2, and Test 3, in Section 4. In all analyses, a variance and two length scales must be specified. In this section we present two verification efforts:

1. using variance and length scale analyses from the same data analys is that produced the harmonic spikes

2. using variance and length scales of quasi-theoretical derivation.

Test 1 was analyzed in both the 8.5- and 17-min record lengths. Since verification is much better in the former case, it is presented in greater detail.

Observed variances were reported in Section 4. Adoption of an observed length scale value is a process requiring some description. Such a length scale is always in the along-wind direction. For the u-component, or horizontal, wind speed we designated this scale as $\left(L_{u}\right)_{X}$.

\subsection{VERIFICATION KITH OBSERVED VARIANCE AND LENGTH SCALES}

\subsubsection{Adoption of Length Scale Values}

Observed length scales are also available from the sample spectral analys is program after some interpretation of output. Referring back to Equations (2.6) and (2.7), we see that the integral of the autocorrelation function must converge in order for the length scale to be defined. Autocorrelation functions of samples of $u$ or $v$ component turbulence frequently do not converge. Therefore, some other criterion must be sought if a length scale value is to be used. Frequently, the value of the integral at its first maximum is taken as the value of the length scale. This is what we call an observed value. This is also the first point where the autocorrelation function becomes negative. If the data set contains data from several anemometers exposed at the same level so that the individual data records should be part of the same ensemble, there may be sufficient disagreement among observed values that an average value taken over all individual values showing relative agreement is the best interpretation. 
A second qualifying aspect is data handling before analysis. Most analysts remove trends from data before spectral analysis. Linear trends were removed from the data analyzed for this report. Such trend removal also significantly reduces calculated variance and integral scale. In the analys is to be presented here, we use the results of analyzing linearly detrended data of 8.5- and 17-min periods, as were used by Connell and George (1983). The values of the length scale $\left(L_{u}\right)_{x}$ were estimated from this analysis. Values for $\left(L_{u}\right)_{y}$, the length scale of horizontal wind speed in the lateral direction, were assumed to be 0.4 $\left(L_{u}\right)_{x}$ (see Counihan 1975). For the stable case, a larger value of $\left(L_{u}\right)_{y}, 0.5$ $\left(L_{11}\right)_{x}$, was used. This was necessary because the theoretical spectrum produced by the component program described in Section 3, using $\left(L_{u}\right)_{y}=0.4\left(L_{u}\right)_{x}$, Test 2, had negative values in it. In other words the program produces an autocorrelation function that is not positive-definite when the length scale is too short.

The length scales selected were

\begin{tabular}{|c|c|c|}
\hline & $\left(L_{u}\right)_{x}(m)$ & $\left(L_{u}\right)_{y}(m)$ \\
\hline $\begin{array}{l}\text { Test } 1 \\
\text { Test } 2 \\
\text { Test } 3\end{array}$ & $\begin{array}{r}112 \\
36 \\
90\end{array}$ & $\begin{array}{l}45 \\
18 \\
36\end{array}$ \\
\hline
\end{tabular}

\subsubsection{Variances in the Harmonic Bands and Spectra}

The variances in the harmonic bands, calculated and measured, are shown in Figure 5.1. One graph is presented for each of the three tests.

In all three cases the modeled values are found both above and below the measured ones. Therefore, the modeled estimates are of about the right magnitude. In all three cases the modeled values decrease more rapidly with increasing frequency than do the measured values. That is, the absolute value of the slope is less for the curve representing the measured variances than for the curves representing the modeled variances. Therefore, it will be instructive in the next section to use several derived length scales so that the sensitivity of both level and slope of the modeled values to different selection of the length scale may be shown. (Change of variances changes all modeled values by the same ratio as the ratio of variance change.)

The spectra that were integrated to obtain the modeled values are shown in Figure 5.2 . 


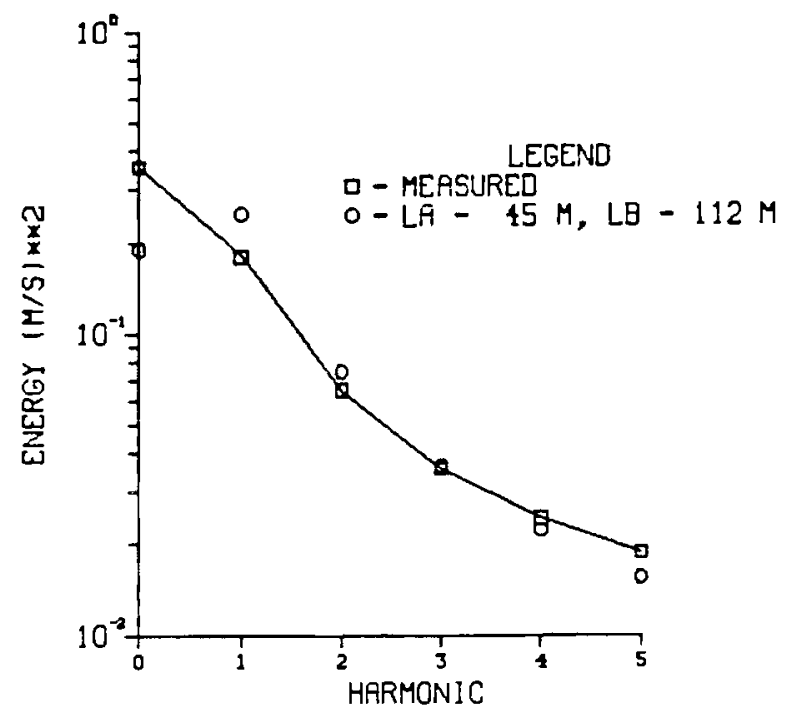

(a)
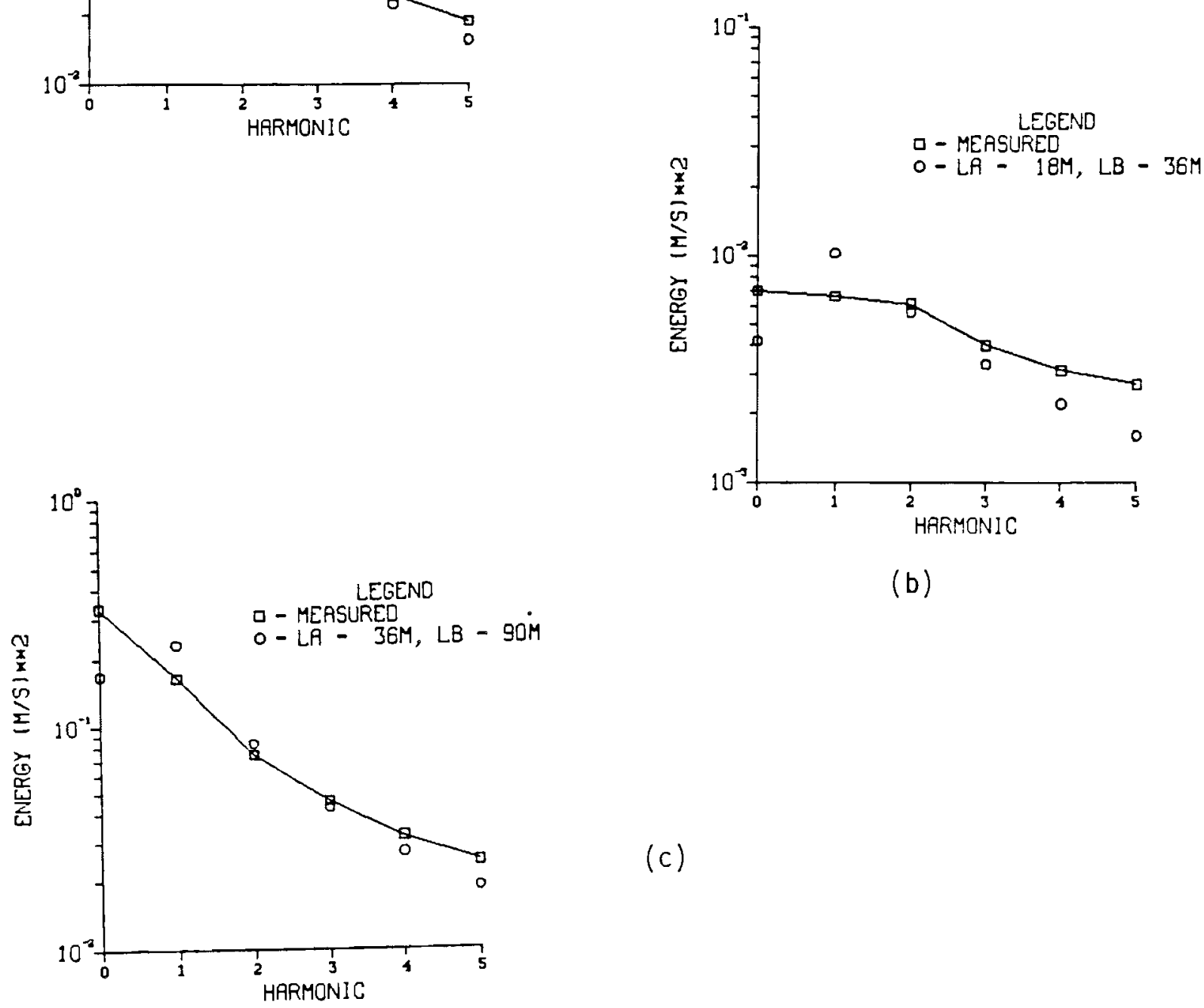

(b)

FIGURE 5.1. Measured and Modeled Variances for Five Harmonics: (a) Test 1, Slightly Unstable; (b) Test 2, Stable, (c) Test 3, Unstable. 


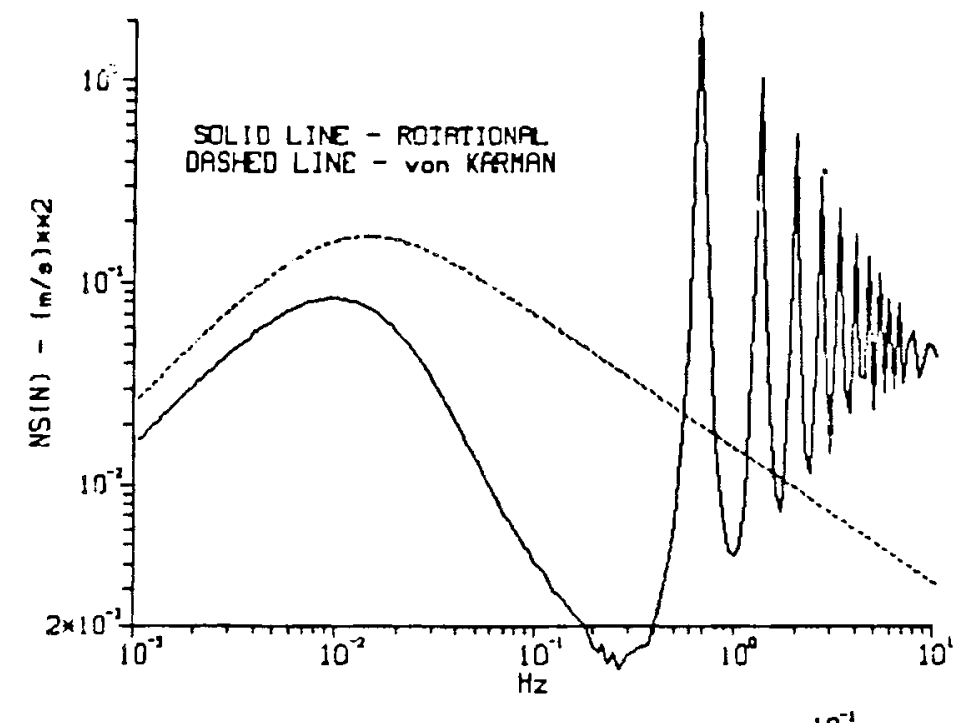

(a)

U-8.21M/S, Z-30.5H, R-j9.05H, NO-0.557HZ SIOU $-0.79 M / S, 20-0.005 \mathrm{M}$, LA-45M, LB-112M

(b)

U-5.51H/5, Z-30.5M, R-19.05M, NO-0.667HZ 51GU-U. I SMVS, 20-0.005K, LF-: BM, LE-36M
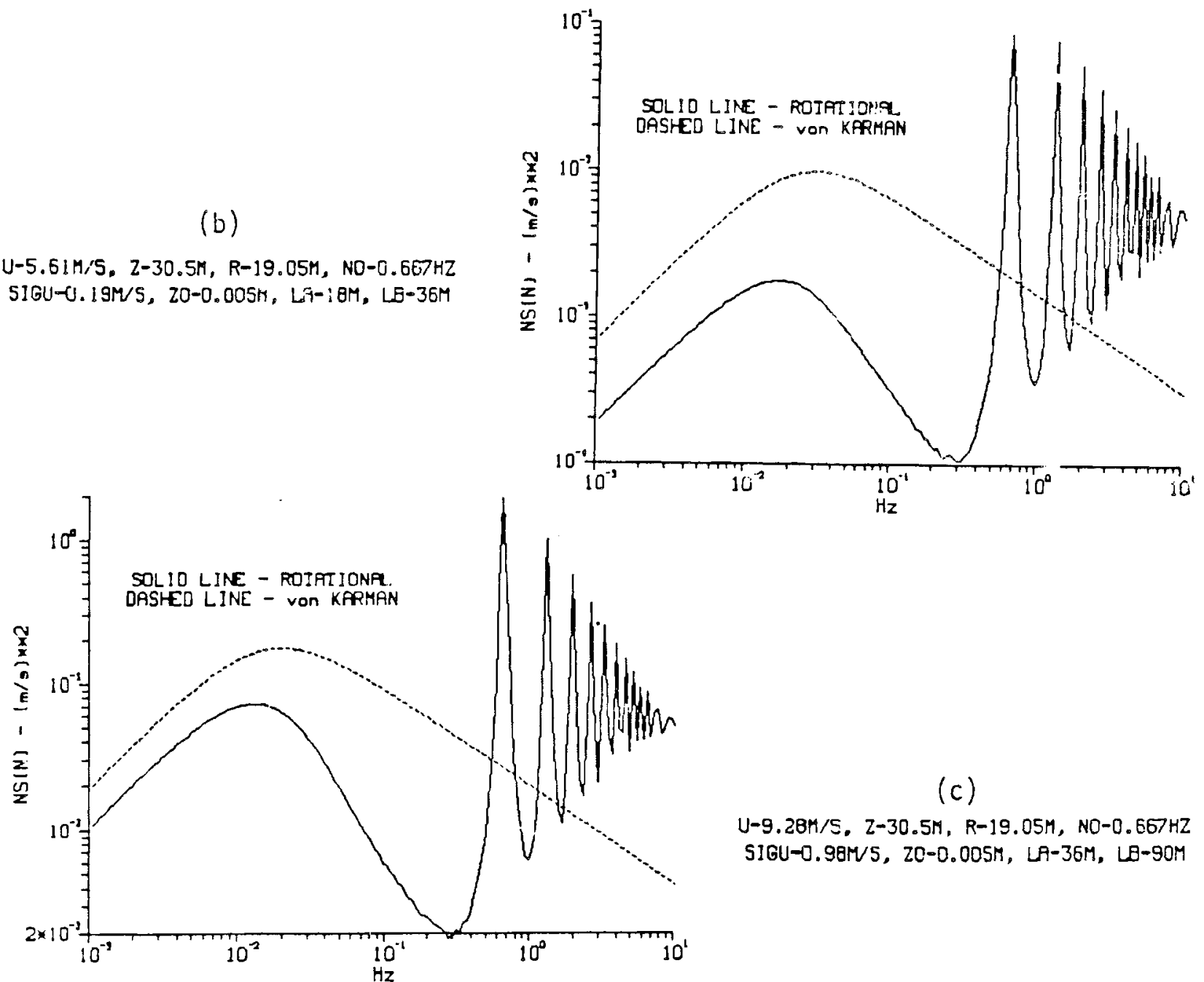

(c)

$U-9.28 M / 5, Z-30.5 M, R-19.05 M, N O-0.667 \mathrm{HZ}$ SIGU $-0.98 M$ S, ZO-0.005M, LA-36M, LE-9OM

FIGLRE 5.2. Rotationally Sampled Spectra: (a) Test 1 Neutral; (b) Test 2 Stable; (c) Test 3 Unstable 
These spectra are quite similar, except that the stable case departs more from the von Karman/Eulerian spectrum than the other spectra.

The correspondence of the rotational spectra from data analysis and from the model for Test 1 is shown in Figure 5.3. This fit is also quite good, although the troughs in the modeled spectrum are noticeably deeper. The difference could be due to noise in the data. The spectrum from data terminates at the fifth harmonic because the higher harmonics are beyond the Nyquist frequency of the data.

One way to make the troughs of the spectra from the data deeper is to subject the data to low-pass filtering at each anemometer before doing the rotational sampling (see George 1984). This has interesting implications discussed in the next section.

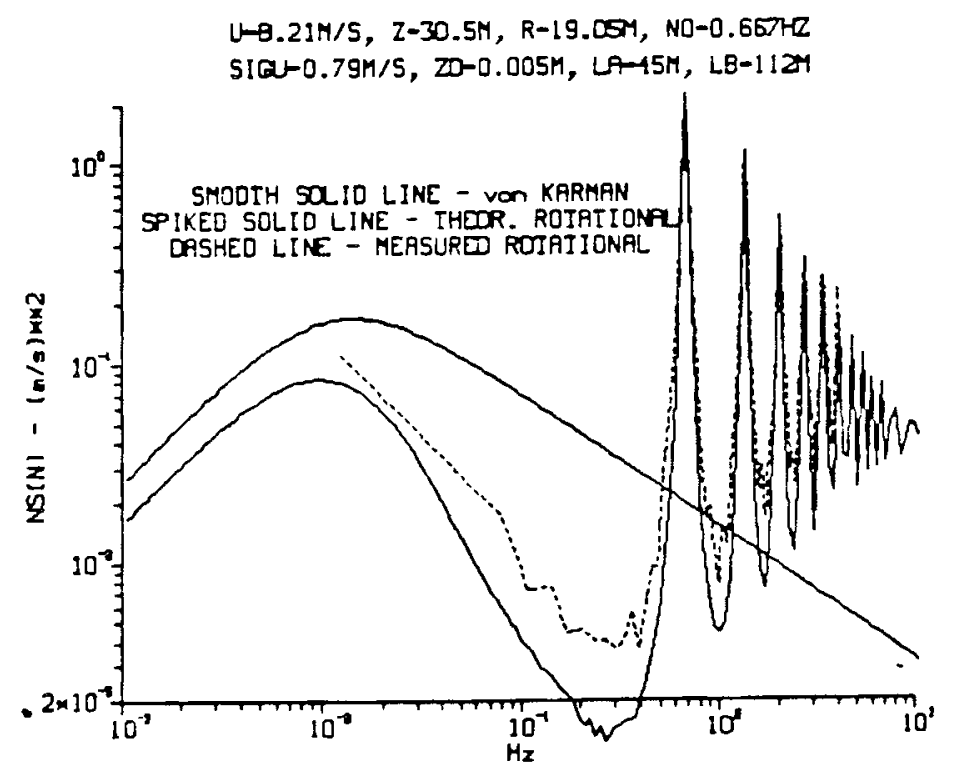

FIGURE 5.3. Rotationally Sampled Spectra for Test 1 


\subsection{VERIFICATION AND SENSITIVITY STUDY USING CALCULATED AND ARBITRARY VARIANCES} AND LENGTH SCALES

Rotational spectra applicable for neutral stability and small deviations therefrom have been produced using calculated values of turbulence rms and length scale. The stability limitation is necessary because there are no diabatic terms in the model. A turbulence rms value may be calculated using the mean wind speed of $8.21 \mathrm{~m} / \mathrm{s}$ in Equations (A.6) and (A.7). This yields

$$
\sigma_{u}=0.904 \mathrm{~m} / \mathrm{s} \text {. }
$$

Using Equation (A.7) to calculate a value of $\left(L_{u}\right)_{x}$, we obtain

$$
\left(L_{u}\right)_{X}=128 \mathrm{~m} .
$$

If we assume that $\left(L_{u}\right)_{y}$ is $40 \%$ of $\left(L_{u}\right)_{X}$, we obtain

$$
\left(L_{u}\right)_{y}=51 \mathrm{~m} \text {. }
$$

In the following demonstration, we use the two values of length scale to demonstrate the sensitivity of the model by running four scenarios with length scales as follows:

$$
\begin{array}{ll}
L_{a}=128 \mathrm{~m}, & L_{b}=128 \mathrm{~m} \\
L_{a}=128 \mathrm{~m}, & L_{b}=51 \mathrm{~m} \\
L_{a}=51 \mathrm{~m}, & L_{b}=128 \mathrm{~m} \\
L_{a}=51 \mathrm{~m}, & L_{b}=51 \mathrm{~m}
\end{array}
$$

where the values in the third scenario correspond to the assumptions above. Note that the third scenario is the only one approaching the measured values. The variances in the harmonic bands are plotted along with the observed variances in Figure 5.4. The corresponding spectra are given in Figure 5.5.

There are several interesting observations to make.

1. The modeled harmonic band variances change more with change of $L_{a}$ than with change of $L_{b}$ except at the first harmonic, $1 P$. 


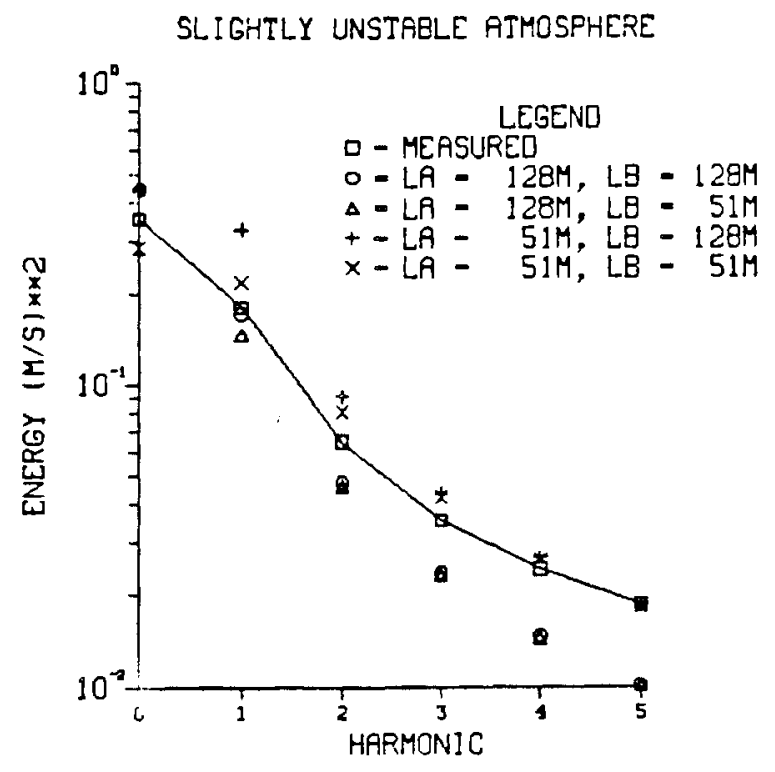

FIGURE 5.4. Measured and Modeled Variances for Five Harmonics Using Four Length Scale Scenarios

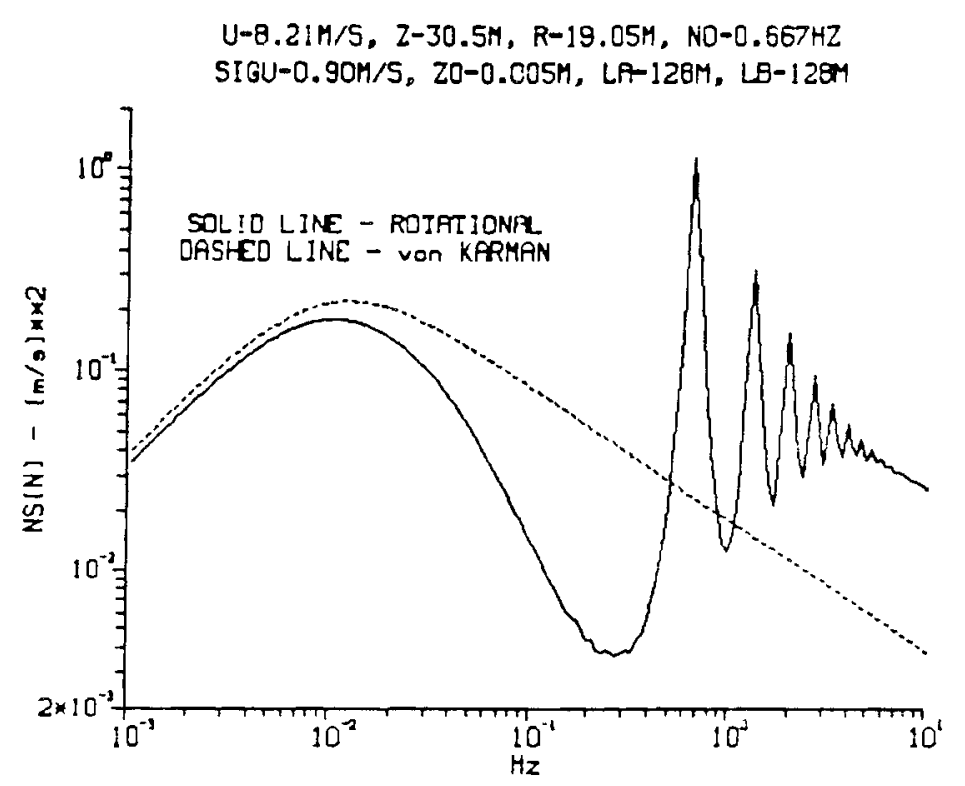

(a)

FIGURE 5.5. Rotationally Sampled Spectra for Four Length Scale Scenarios 


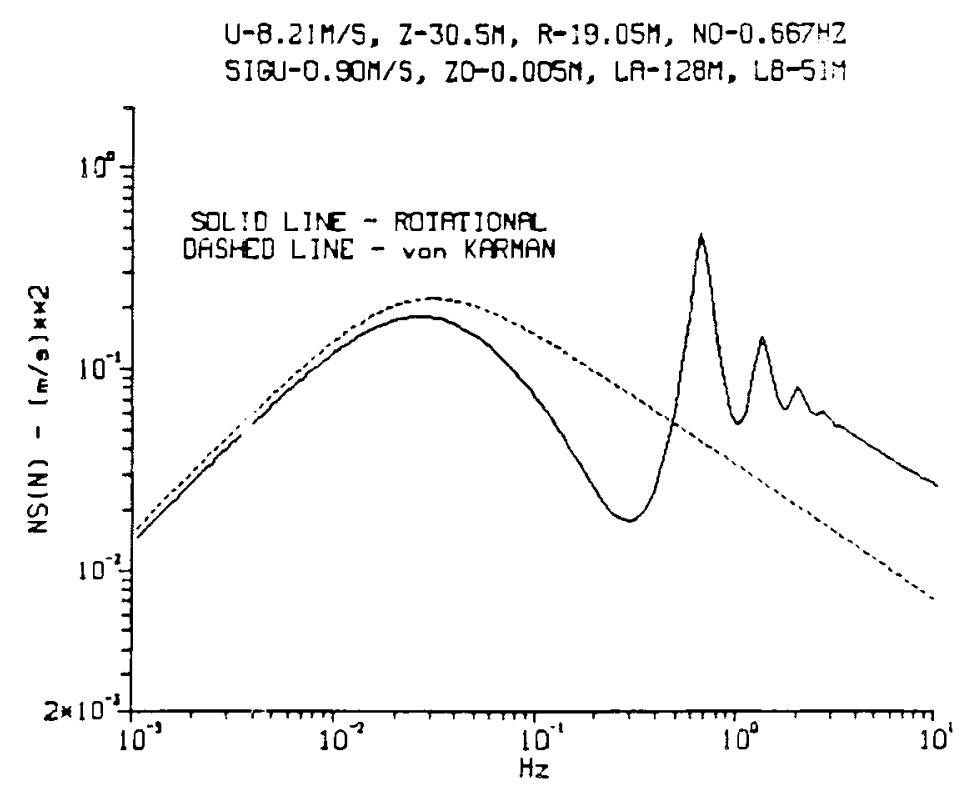

(b)

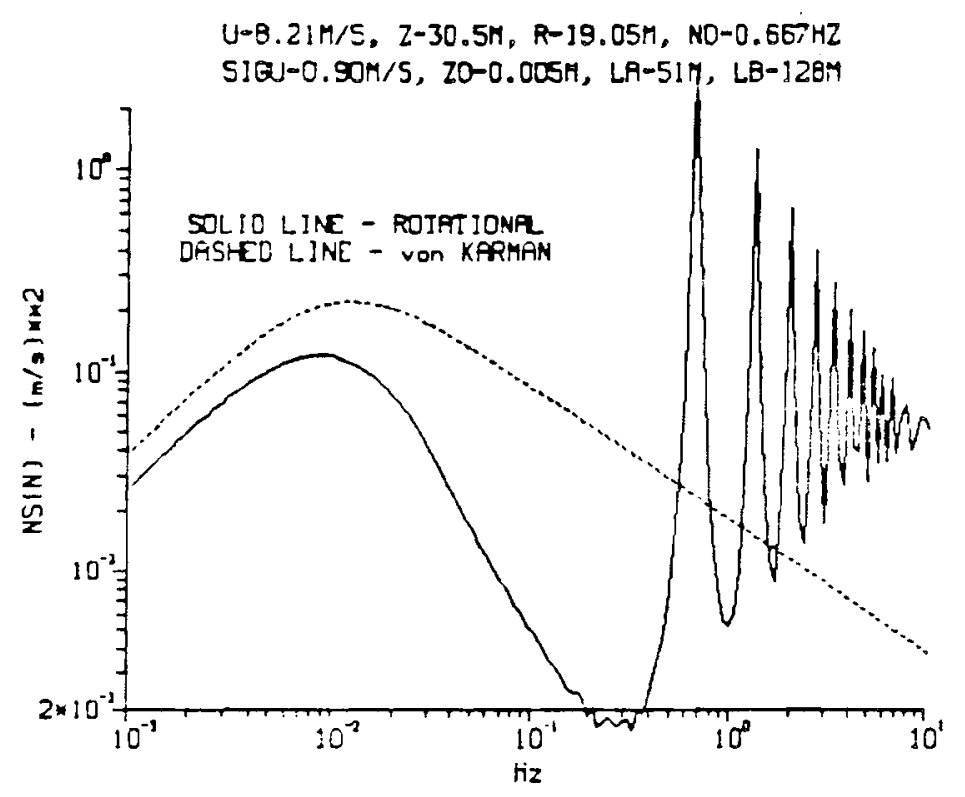

(c)

FIGURE 5.5. (Continued) 


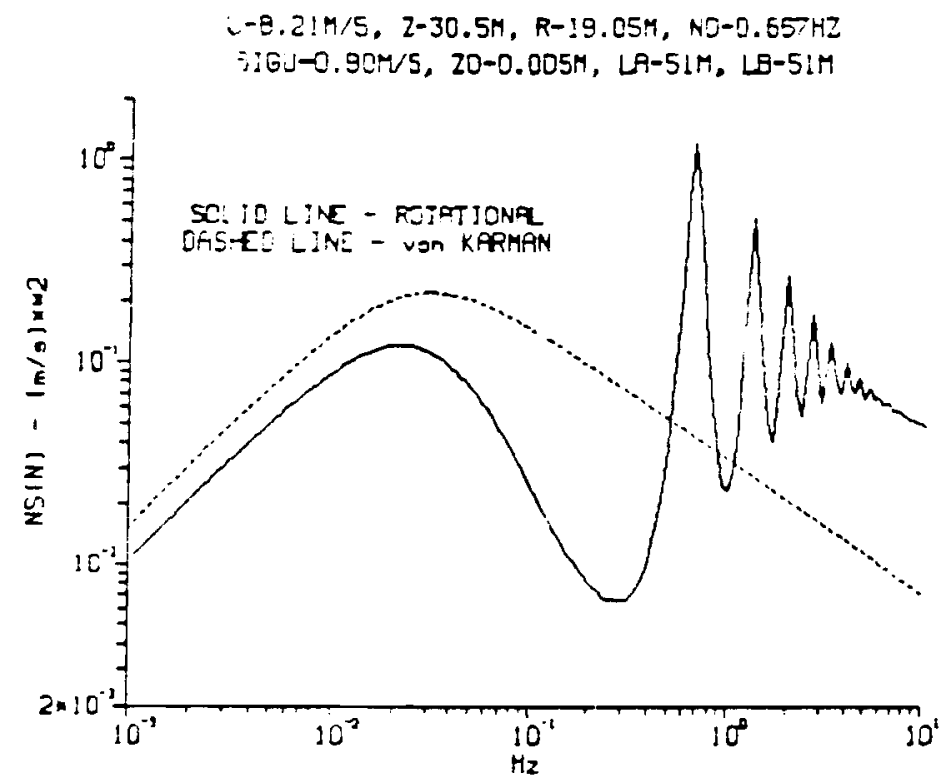

(d)

FIGURE 5.5. (Continued)

2. Reduction of $L_{x}$ somewhat reduces the decrease of energy with harmonic number (slope of a line connecting points).

3. The best fit is obtained not with the third scenario, but with the fourth, which used the shorter length scale for both $L_{a}$ and $L_{b}$.

4. The rotational spectrum from data analysis, Figure 5.3 , obviously fits the theoretical spectrum from the observed values better than any of the theoretical spectra in Figure 5.5 except possibly the third, which is based on similar values of $L_{a}$ and $L_{b}$.

5. Decreasing $L_{b}$ while holding $L_{a}$ constant decreases the contrast between peak and valley that defines the harmonic spikes. Fewer spikes are defined. Decreasing $L_{a}$ while holding $L_{b}$ constant increases the contrast between peak and valley. Spikes are generated out to greater multiples of the rotation rate.

6. When the data are low-pass-filtered before analysis, thus lengthening $\left(L_{u}\right)_{X}$, the contrast between peaks and valleys is increased. Thus, the behavior of $\left(L_{u}\right)_{x}$ is like that of $L_{b}$ in the model. This fact seems to indicate the need for the scale in the longitudinal direction. Since 
neither of the spectra using identical values for both $L_{a}$ and $L_{b}$ show sufficient contrast between peak and valley, the need for the second distinct length scale is also apparent.

7. The spectra for the two cases whose length scales are the same, first and fourth, appear similar, but there is more variance with the shorter length scales. This shows that increasing variance (which increases all spectral values in direct proportion) and decreasing both length scales (which increases all spectral values but not exactly by the same ratio) has a similar but not identical effect. This is very important. It means that selection of analysis period length and data detrending procedure, as determined by some criterion (probably debatable) of appropriateness to the total physical situation, is not extremely critical. The reason is that the increase of observed variance and increase of observed length scale are compensating features in the determination of the higher frequency portion of the rotational spectrum. However, a distinction in the low-frequency range is possible; see Figure 5.6 .

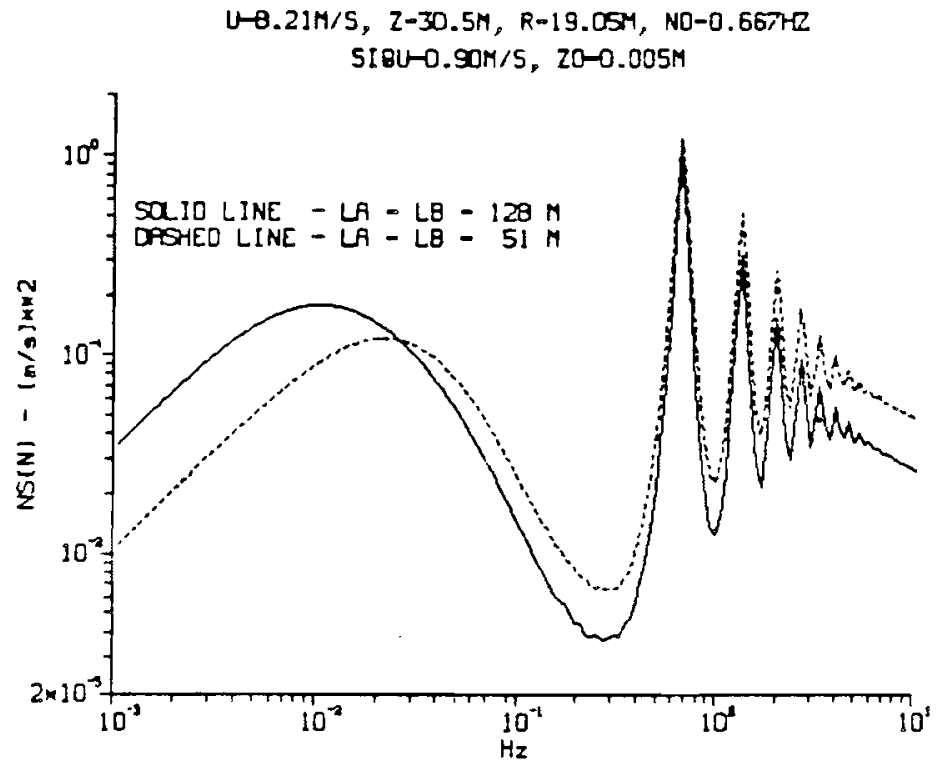

FIGURE 5.6. Comparison of Rotational Spectra for Two Length Scale Scenarios 


\subsection{VERIFICATION FOR THE 17-MIN CASE}

The harmonic band variances and the rotational spectrum for the 17-min case are shown in Figure 5.7. We note that the difference in slope between modeled and measured results is greater in this case than in the 8.5-min cases. This is expected because $L_{b}$ has been increased. It appears that the 8.5-min time frame used in the analysis previous to this report was well chosen.

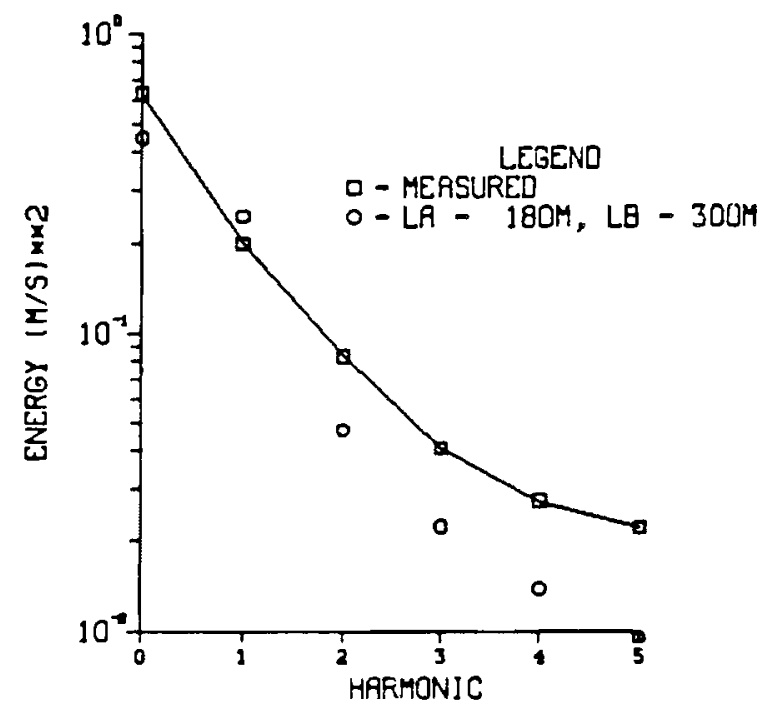

FIGURE 5.7. Comparison of Measured and Modeled Variances for Five Harmonics, Test 1, 17-min

5.4 RUNNING TIME FOR THE MODEL

The running time of this model on iile VAX $11 / 70$ computer is proportional to the length scales used. Typically the runs take about 4 min of execution time. Extreme times were about 2 min for the short length scales used in Test 2 and 12 min for the long length scales used in the 17-min version of Test 1. 


\subsection{CONCLUSIONS}

We conclude that the theoretical model verifies well against measured winds at a VPA with the 8.5-min runs except for the stable case. If such verification can be extended to include measured data from one hot-film device mounted on a rotating blade, expensive measurement programs may be sometimes circumvented by the use of theory.

Modeled verification may be accomplished with physically inappropriate values since increasing variance and decreasing both length scales in the model have a similar but not identical effect.

Because the rotational period is very short compared to even the shortest sample (or data record) period, which was $8.5 \mathrm{~min}$, it seems fair to conclude also that short sampling periods should be preferred for assessment of variance and length scale. The larger values of variance and length scale obtained by making the sample longer have a compensating effect in the rotational analysis, and a direct effect in escalating the cost of running the model. 


\subsection{MODELING THE MEAN WIND SHEAR}

Mean wind shear in the boundary layer can be modeled by the logarithmic wind law for the neutral simple boundary layer, or by Paulson's extension [see Equation (4.2)] for the unstable boundary layer. There is also the log-linear law for simpler stable case [see Equation (4.3)]. Correct modeling depends on the data for surface roughness and the estimation of the Monin-Obukhov length.

once a modeled profile has been obtained, this can be rotationally sampled and the resulting time series subjected to spectral analysis to obtain variances for the harmonic bands. Since one revolution of these values is sufficient, the variances of the bands are those of the individual harmonics of the spectral analysis.

\subsection{SPECTRAL ANALYSIS OF THE MODELED PROFILES}

We assume that the variance obtained for the total wind with the mean shear left in is the sum of the parts obtained by analyzing mean shear only and turbulence only. This assumes that the contribution of the mean shear to the low harmonics is independent of the turbulence with respect to phase.

The differences between the energy in the harmonic bands for the total wind and for the wind with the mean shear removed (from Section 4) are given in Table 6.1 .

TABLE 6.1. Variance in the Shear Contribution to the Measured Harmonic Bands.

\begin{tabular}{|c|c|c|c|}
\hline \multirow[b]{2}{*}{ Band } & \multicolumn{3}{|c|}{$\operatorname{Variances}(\mathrm{m} / \mathrm{s})^{2}$} \\
\hline & Test 1 & Test 2 & Test 3 \\
\hline $1 F$ & 0.1048 & 1.1122 & 0.0732 \\
\hline $2 P$ & 0.0048 & 0.0231 & 0.0038 \\
\hline $3 P$ & 0.0052 & 0.0043 & 0.0041 \\
\hline $4 P$ & 0.0006 & 0.0007 & 0.0020 \\
\hline $5 P$ & 0.0022 & 0.0005 & 0.0032 \\
\hline
\end{tabular}

The corresponding analysis of modeled shear, derived from profile equations, is given in Table 6.2. 
TABLE 6.2. Corresponding Analysis Using Time Series Derived from Profile Equations

\begin{tabular}{|c|c|c|c|}
\hline \multirow[b]{2}{*}{ Band } & \multicolumn{3}{|c|}{ Variances $(\mathrm{m} / \mathrm{s})^{2}$} \\
\hline & Test 1 & Test 2 & Test 3 \\
\hline $1 P$ & 0.1131 & 1.0727 & 0.0924 \\
\hline $2 P$ & 0.0050 & 0.0014 & 0.0043 \\
\hline $3 P$ & 0.0003 & 0.0001 & 0.0003 \\
\hline $4 P, 5 P$ & 0.0 & 0.0 & 0.0 \\
\hline
\end{tabular}

The ratios (modeled value divided by measured value) from these tables are given in Table 6.3 .

TABLE 6.3. Ratios Between Modeled and Measured Values in Tables 6.1 and 6.2 .

\begin{tabular}{|c|c|c|c|}
\hline & & $\begin{array}{l}\text { io of } M \\
\text { easured }\end{array}$ & $\begin{array}{l}\text { eled } \\
\text { alues }\end{array}$ \\
\hline & Test 1 & Test 2 & Test 3 \\
\hline LP & 1.08 & 0.96 & 1.26 \\
\hline $2 P$ & 1.04 & 0.06 & 1.13 \\
\hline $3 P$ & 0.06 & 0.02 & 0.15 \\
\hline
\end{tabular}

Care must be taken not to attach too much meaning to the more favorable ratios in Table 6.3 since the modeled profiles are all functions of estimated values of Monin-Obukhov length (see Section 4). If the length had been estimated at other values, these ratios would have been different. But the ratios are encouracing: they indicate that if the shear can be irodeled correctly, the first, and maybe the first two, harmonic bands can also be modeled correctly. In the higher harmonic bands the shear contribution is unimportant compared to the turbulence contribution. (For the neutral and unstable cases, this is also true of the second harmonic band.)

The unfavorable ratios, showing much more variance in the higher frequency bands for the measured values than for those modeled, are believed to result from inaccuracies in the measured profile (see Table 4.2 and discussion).

In the rotational spectra for mean wind included and mean wind at each anemometer removed (and consequently mean shear deleted), the difference seen in 
the tabulated variances must be in the single harmonic frequency of each spike rather than spread out over the band. This is shown in Figure 6.1, where both are presented on the same graph. Although the difference is scarcely visible in this plot, the contribution to the variance is, nevertheless, important.

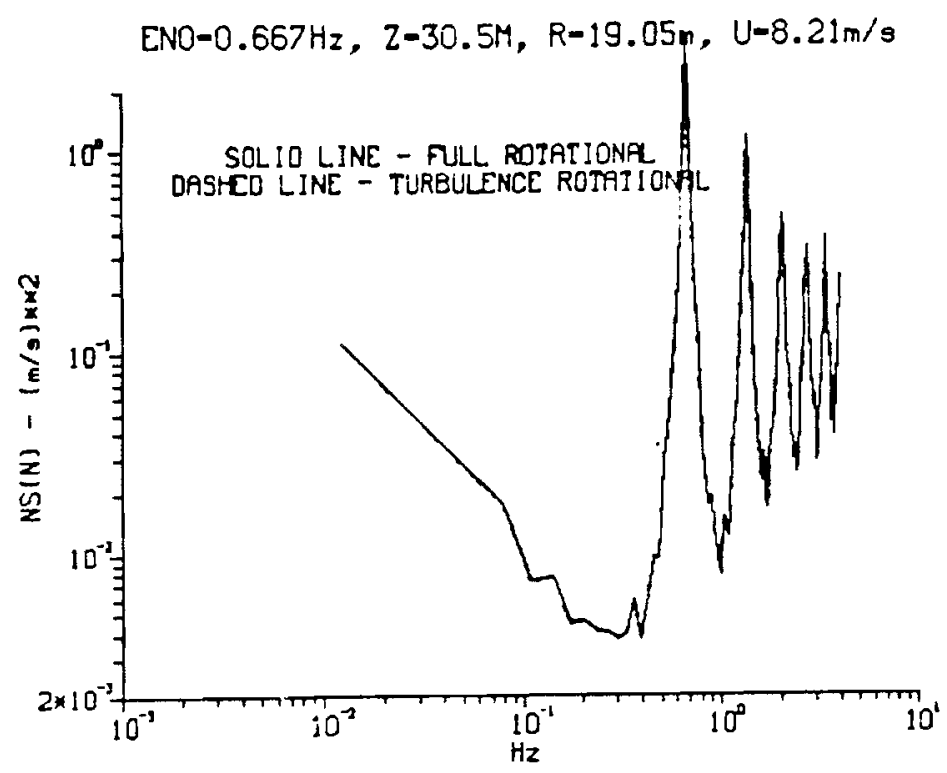

FIGURE 6.1. Rotationally Sampled Spectrum Produced by the Model 


\subsection{CONCLUSIONS}

We conclude that the energy of the first five harmonics of wind speed data (frequencies $1 P, 2 P \ldots . .5 P$ ), rotationally sampled in the plane of rotation of the blade of a horizontal-axis wind turbine, can be well represented by the theoretical model described in this report. Qualifications to this conclusion are: 1) that the rotationally sampled data used for verification were constructed by sampling about a circle of anemometers in a vertical plane array rather than by collecting continuous data as could be done on a device attached to a rotating blade, and 2) that the verification was well demonstrated for tests conducted in the slightly unstable atmosphere, which may be taken to represent the neutral atmosphere, and in the definitely unstable atmosphere, but was less convincing in a test conducted for the stable atmosphere.

Analytically, the energy in the harmonics comes from two phenomena: the vertical shear of the mean wind and the turbulence. Except possibly in the stable case, the important contribution of vertical shear is entirely to the first harmonic, 1P. This energy was well modeled for the neutral and unstable cases; ratios of energy calculated from the model to energy calculated from data analysis were well within the 0.90 to 1.10 bracket.

From measured turbulence analys is (mean wind shear excluded), we found that all of the first 5 harmonics have significant turbulent energy levels. The ratios of energy calculated by the model to energy calculated by analysis of the data of the neutral test decreased monotonically from 1.38 at $1 \mathrm{P}$ to 0.74 at 5P. Comparable ratios were obtained by applying the same verification exercise to the data of the unstable test. The attempt to similarly model rotational turbulence in the stable atmosphere was less successful.

The measured energy in a harmonic decreased in all cases as harmonic number increased. The modeled decrease was always steeper than the measured decrease, as shown by the decreasing set of ratios in the previous paragraph. This difference could result in part from noise in the rotationally sampled data, caused by any persistent anomaly of the data level at a single anemometer in the rotationally sampled $r i n g$. However, comparison of mean wind measurements for a 17-min period and an included 8.5-min period indicated that such an anomaly could be natural. 
Among the input parameters to the model are the turbulence variance $\left(\sigma u^{2}\right)$ and the longitudinal and lateral length scales of the $u$ component of turbulence. The length scale in the longitudinal direction $\left(L_{u}\right)_{x}$ may be calculated from data analysis. The length scale in the lateral direction $\left(L_{u}\right)_{y}$ is estimated at $40 \%$ of $\left(L_{u}\right)_{x}$, if it cannot be estimated from specific measurements. Both $\sigma_{u}{ }^{2}$ and $\left(L_{u}\right)_{x}$ may be too large if the data analysis period is too long and nonstationarity of the wind grossly affects the calculations. A measurement period of about 8.5 min for normal boundary layer conditions seems to work best. Fortunately, the mathematical effects on model calculations from excess in $\sigma_{u}$ on the one hand and excess in the two length scales on the other hand are to a large extent compensating. Therefore, the sensitivity of the model to an increase of these parameters caused by nonstationarity is much less than would be the case if model sensitivity to concomitant changes was not compensating.

A reasonably good verification of theory was also obtained using a theoretically calculated variance and a value of $\left(L_{u}\right)_{x}$ that was about four times the measuring height. Sensitivity tests performed by varying the two length scales indicate that the model is more sensitive to variation of $\left(L_{u}\right)_{y}$ than of $\left(L_{u}\right)_{x}$. Several other conclusions from this exercise are listed at the end of Section 5.2 .

The model is economical to run. Execution time depends on the length of autocorrelation function needed to achieve convergence, and this depends on the value of $\left(L_{u}\right)_{x}$ chosen -- another reason for avoiding an excessive value that results from too long a data sampling time. One to two minutes is a representative execution time on the $\operatorname{VAX} 11 / 70$. 


\subsection{REFERENCES}

Businger, J. A., J. C. Wyngaard, Y. Izumi, and E. F. Bradley. 1971. "Fluxprofile Relationships in the Atmospheric Surface Layer." Jour. of the Atmospheric Sciences. 28:181-189.

Chan, S. M., D. C. Powe11, M. Yoshimura, and D. H. Curtice. 1983. "Operations Requirements of Utilities with Wind Turbine Generation." IEEE Transactions on Power Apparatus and Systems. Volume PAS-102 No. 9. ISSN 0018-9510. IEEE Power Engineering Society, New York, New York.

Connel1, J. R. 1981. "The Spectrum of Wind Speed Fluctuations Encouitiered by a Rotating Blade of a Wind Energy Conversion System." Solar Energy, $29: 363-375$.

Connel1, J. R., and R. L. George. 1983. "A New Look at Turbulence Experienced by a Rotating Wind Turbine." Paper presented at Energy Sources Technology Conference and Exhibition, January 30-February 3, 1983, Houston, Texas.

Counihan, J. 1975. "Review Paper - Adiabatic Atmospheric Boundary Layers: A Review and Analysis of Data from the Period 1880-1972." Atmospheric Environment. 9:871-905.

Dyer, A. J. 1974. "A Review of Flux-Profile Relations." Boundary-Layer Meteorology. $7: 363-372$.

George, R. L. 1984. Simulation of Winds as Seen by a Rotating Vertical Axis Wind Turbine Blade. PNL-4914, Pacific Northwest Laboratory, Richland, Washington.

Paulson, C. A. 1970. "The Mathematical Representation of Wind Speed and Temperature in the Unstable Surface Layer." Journal of Applied Meteorology. 9:115-130. 
.

• 
APPENDIX

RELATIONSHIP OF ROTATIONAL TO EULERIAN SPECTRA 
- 


\section{RELATIONSHIP OF ROTATIONAL TO EULERIAN SPECTRA}

In this appendix, we demonstrate the correspondence of the rotational spectrum to the corresponding Eulerian spectrum, the von Karman u-component spectrum, when the rotation rate is reduced to zero. Also, the von Karman spectrum is compared with the more state-of-the-art Kaimal u-component spectrum for neutral stability: There are some problems here, as will be shown below. Therefore, the principal point we can make is that we advocate the method given in this report because, in spite of the theoretical problems, it may be successfully used to model blade-bending moments.

The first step is made by plotting the spectrum that results from Fourier transformation of the covariance function of Equation (2.1) when the rotational effort is omitted. In this case, $\Omega$ is zero, $x$ and $r$ are identical, and the second term in the summation vanishes, leaving

$$
\left(R_{11}\right)_{x}=\frac{2}{\Gamma(1 / 3)} \quad \sigma^{2}\left(\frac{x}{2 L}\right) 1 / 3\left\{K_{1 / 3}\left(\frac{x}{b}\right)\right\}
$$

where $\left(R_{11}\right)_{x}$ is the correlation of the $u$ component in the $x$ direction. This correlation function was expected to transform into the von Karman spectrum for the $u$ component, which is given by

$$
\frac{\mathrm{nS}_{u}(n)}{\sigma_{u^{2}}}=\frac{4 \mathrm{~F}}{\left[1.0+(1.339 \times 2 \pi \mathrm{F})^{2}\right]^{0.8333}}
$$

where

$$
\mathrm{F}=\mathrm{nL}_{\mathrm{b}} / \mathrm{U}
$$


Several points about this spectrum deserve discussion. First, since there are no diabatic terms, the spectrum models the neutral atmosphere rather than the unstable or the stable atmosphere. Neutral stability has widely been regarded as sufficient for wind energy applications because atmospheric stability approaches neutrality during high operational wind speeds (Frost and Shieh 1981). However, during some operational conditions, the atmosphere is unstable and turbulence is more intense (see Powel1 1984). For these periods, such a spectrum may underpredict the turbulence in the rotational spikes by a factor of approximately $25 \%$ to $50 \%$ depending on the degree of instability. Second, the spectrum correctly models the high-frequency range of isotropic turbulence where $n S_{u}(n)$ decreases with the $2 / 3$ power of $n$. A third feature is that the highfrequency range may not properly model vertical variation of the spectrum unless the length scale $L_{b}$ is proportional to height. Panofsky and Dutton (1984) point out that the length scale of the $u$ component in the alongwind direction $\left(L_{u}\right)_{x}$ increases more slowly with height than the first power in neutral conditions in simple terrain. Therefore, they do not recommend von Karman spectra for atmospheric modeling.

However, the same objection applies to the Kaimal spectrum, as well as to any other state of the art spectrum for neutral stability. Therefore, regardless of which spectrum. we use, we will have to live with these objections.

When the zero-rate rotational spectrum was compared to Equation (A.2), it was found to be too low at low frequencies and too high at high frequencies. However, it was found to coincide very well with the following:

$$
\frac{\mathrm{nS}_{U}(\mathrm{n})}{\sigma_{U^{2}}}=\frac{4 \mathrm{~F}}{1.339\left[1.0+(2 \pi F)^{2}\right]^{0.833333}}
$$

This equation is like (A.2) except that one coefficient, the 1.339, has been relocated. We shall call this the von Karman variant spectrum. The plot is shown in Figure A.1. Why the correlation function by von Karman transforms into the variant spectrum is not known. 


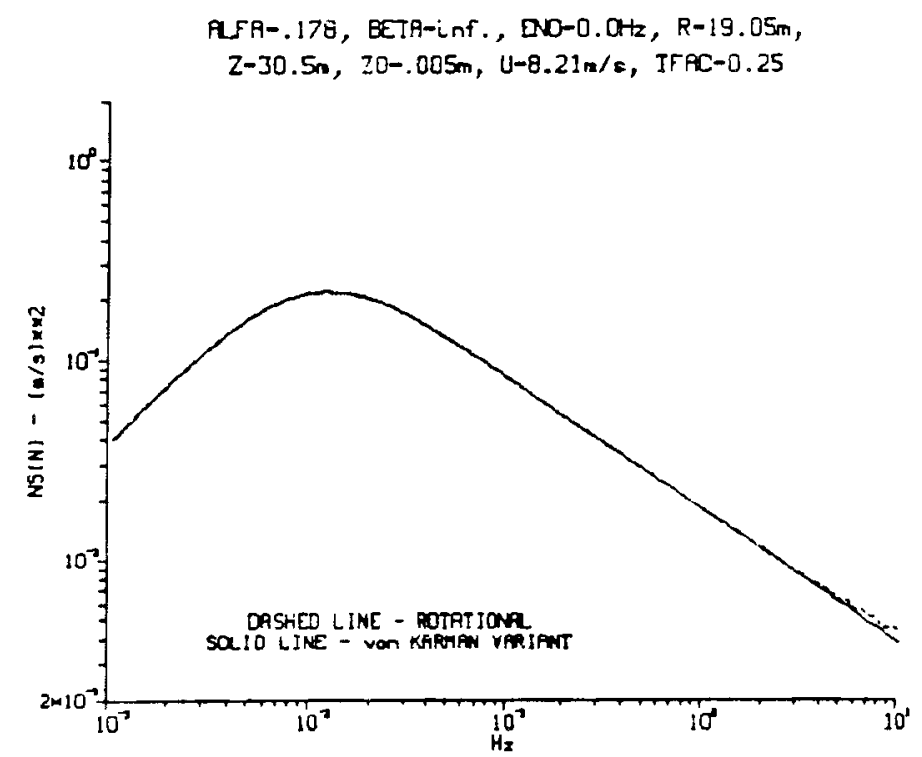

FIGURE A.1. Comparison of "Rotational Spectrum" at Zero Rotation Rate with von Karman Variant Spectrum

The distinction between is important insofar as the plots of the von Karman spectrum and the variant spectrum differ. This comparison is shown in Figure A.2.

Obviously, the variant is simply a shift of the original to higher frequency. Inasmuch as the $y$-axis difference varies from $33 \%$ on the left side to $22 \%$ on the right side, the difference is of some significance.

Another interesting comparison is between the von Karman variant spectrum and the Kaimal u-component spectrum (Kaimal et al. 1972), which is considered state of the art for neutral stability by meteorologists. This is given by

$$
\frac{n S(n)}{u_{\star}^{2}}=\frac{105 f}{[1.0+33 f]^{1.666667}}
$$




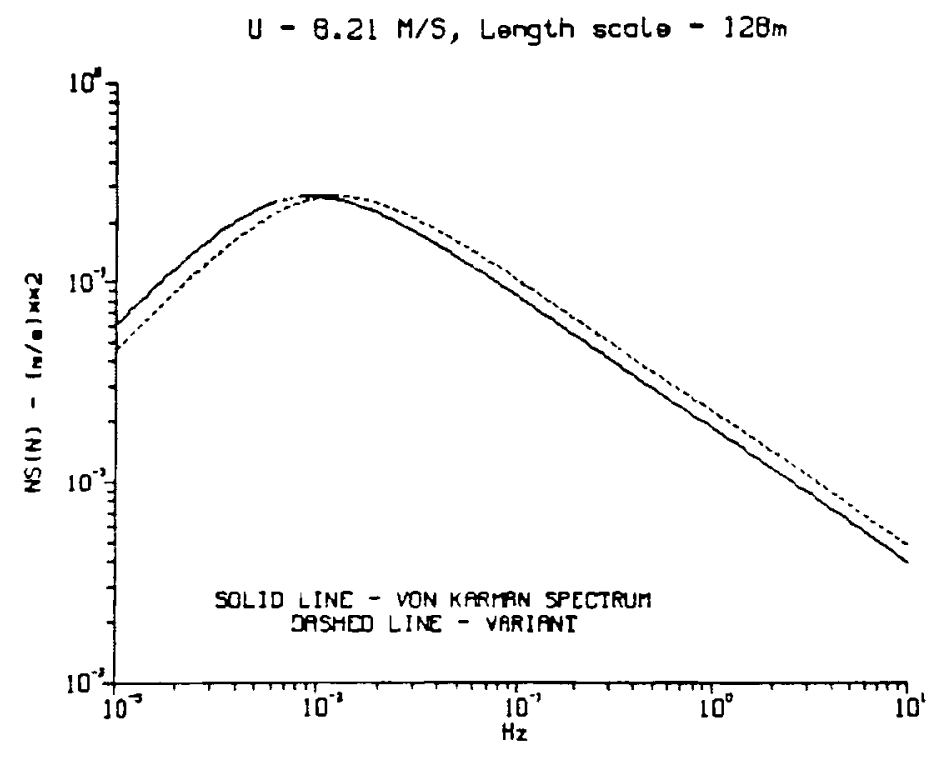

FIGURE A.2. Comparison of von Karman Spectrum and Variant Spectrum.

where

$f=n z / U$

$z=$ height

$u_{\star}=$ is the friction velocity given by the logarithmic wind law:

$$
u_{\star}=0.4 \mathrm{U} / \ln \left(\mathrm{z} / \mathrm{z}_{0}\right)
$$

$z_{0}=$ is the surface roughness length.

Note that height serves directly as the length scale here; therefore the length scale is defined as the first power of height.

The Kaimal spectrum and the von Karman variant spectrum are compared in Figure A.3. This plot was facilitated by setting

$$
\begin{gathered}
\sigma_{u}=2.4 u_{\star} \\
\left(L_{u}\right)_{x}=4.2 \mathrm{z} .
\end{gathered}
$$




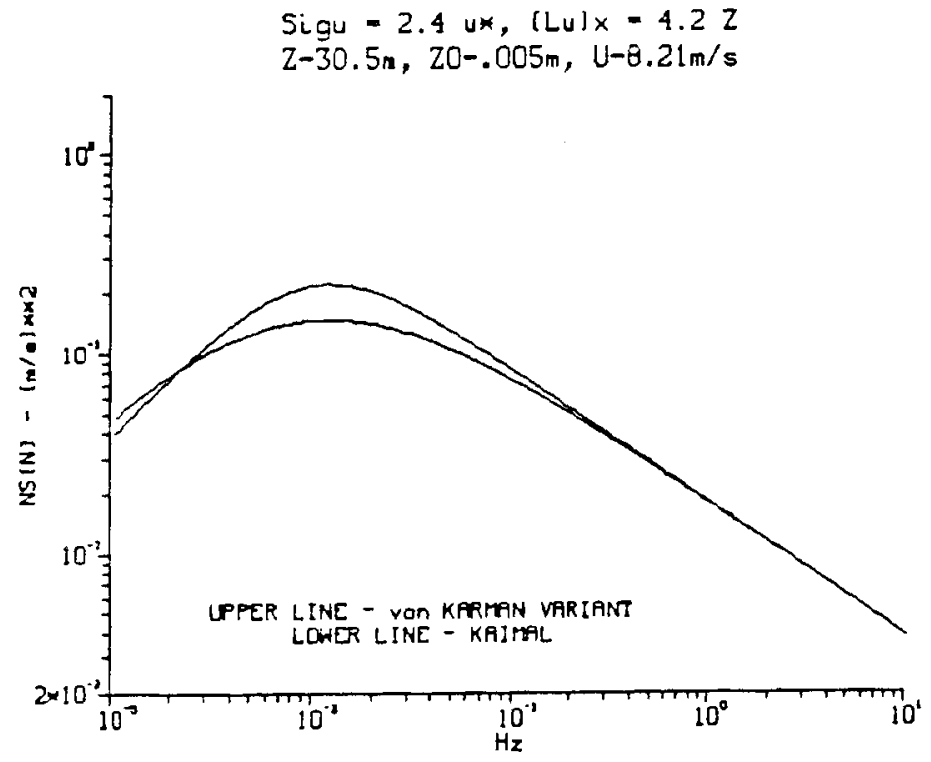

FIGURE A.3. Comparison of Kaimal u Spectrum and the von Karman Variant.

Neither of these are arbitrary fabrications. The first is in agreement with Panofsky and Dutton (1984). The second may be obtained using Kaimal's methods (Kaimal 1973). Although the subject of this paper is spectral description for the stable atmosphere, the reseult applies reasonably well to the neutral atmosphere. 


\section{APPENDIX REFERENCES}

Frost, W. and C. F. Shieh. 1981. Guidelines for Siting WECS Relative to SmallScale Terrain Features. DOE/ET/20242-78-1, Available from the National Technical Informatịon Service, Springfield, Virginia.

Kaima1, J. D., J. C. Wyngaard, Y. Izumi, and 0. R. Cote. 1972. "Spectral Characteristics of Surface-Layer Turbulence." Quarterly Journal of the Royal Meteorological Society. 98:563-589.

Kaima1, J. D. 1973. "Turbulence Spectra, Length Scales and Structure Parameters in the Stable Surface Layer." Boundary Layer Meteorology. 4:289-309.

Panofsky, H. A., and J. Dutton. 1984. Atmospheric Turbulence. Wiley-Interscience, New York.

Powe11, D. C. 1984. Meterorlogical Analys is for Clusters of Wind Turbines: Interim Report. PNL-5024, Pacific Northwest Laboratory, Richland, Washington. 


\section{DISTRIBUTION LIST}

N.o. of

Copies

\section{OFFSITE}

Carl Aspliden

Battelle Memorial Institute Washington Office

2030 M Street NW

Washington, DC 20036

J. Cadogan

Department of Energy

Wind Energy Technology Division

1000 Independence Avenue

Forrestal Building, P.oOm $5 \mathrm{HO} 48$

Washington, DC 20585

D. F. Ancona

Department of Energy

Wind Energy Technology Division

1000 Independence Avenue

Forrestal Building, Room $5 \mathrm{H} 048$

Washington, DC 20585

G. P. Tennyson

Department of Energy

Albuquerque Operations Office

P.0. Box 5400

Albuquerque, NM 87110

30 DOE Technical Information Center

Peter Lissaman

Aerovironment, Inc.

$145 \mathrm{Vista}$ Avenue

Pasadena, CA 91107

Tom Gray

American Wind Energy Association

1516 King Street

Alexandria, VA 22314

W. A. Vachon

P.0. Box 149

Manchester, MA 01944
No. of

Copies

S. J. Hightower

Bureau of Reclamation

Denver Federal Center

Building 67 , Code 254

Denver, Co 80225

Wi11 i Sadeh

Department of Civil Engineering

Colorado State University

Fort Collins, CO 80523

V. A. Sandborn

Department of Civil Engineering

Colorado State University

Fort Collins, CO 80523

2 Dr. Edgar DeMeo/Frank Goodman, Jr. Electric Power Research Institute 3412 Hillview Avenue

Palo Alto, CA 94303

R. L. George

TERRA Sciences, Inc.

7555 W. 10th Avenue

Lakewood, CO 80214

Tom Hiester

Flowind Corporation

1183 Quarry Lane

Pleasanton, CA 94566

2 J. M. Kos/Eugene Di Valentin Hamilton Standard

Bradley Field Poad

Windsor Locks, CT 06096

G. L. Park

Department of Electrical

Engineering

Michigan State University

East Lansing, MI 488 ? 4 
No. of

Copies

David Spera

NASA/Lewis Research Center

21000 Brookpark Road

Cleveland, $\mathrm{OH} \quad 44135$

Phillip French

NASA Scientific and Technical Information Facility

P.0. Box 8757

Baltimore/Washington International Airport

Baltimore, MD 21240

J. C. Kaima 1

National Oceanic and Atmospheric Administration/Environmental Research Laboratories/Wave

Propagation Laboratory

3000 Marine Street

Boulder, CO 8030 ?

G. M. Gregorek

Aeronautics and Astronautics

Research Lab

Ohio State University

2300 W. Case Road

Columbus, $\mathrm{OH} 43220$

Peter M. Moretti

Oklahoma State University

Mechanical and Aerospace

Engineering

Engineering North 218

Stillwater, OK 74074

Dr. H. A. Panofsky

6222 Agee Street \#5

San Diego, CA 92122

J. Dutton

Department of Meteorology

Pennsylvania State University

University Park, PA 16902

Andrew Trenka

Solar Energy Research Institute

Rocky Flats

P.0. Box 464

Golden, C0 80401
No. of

Copies

E. Kadlec

Sandia Laboratories

Division 5443, P.0. Box 5800

Albuquerque, NM 87115

Robert Noun

Solar Energy Research Institute

1617 Cole Boulevard

Golden, C0 80401

Sherman M. Chan

Systems Control, Inc.

1801 Page Mill Road

P.0. Box 10025

Palo Alto, CA 94303

R. H. Kirchhoff

Department of Mechanical

Engineering

University of Massachusetts

Amherst, MA 01003

Earl L. Davis

U.S. Windpower, Inc.

2305 S. Vasco Road

Livermore, CA 94550

H. Tieleman

Department of Engineering Science \& Mechanics

Virginia Polytechnic Institute and State University

Blacksburg, VA 24061

Susan Hosch

Washington State Energy Office

400 E. Union Avenue, ist Floor

OTympia, WA 98504

Farrell Smith Seiler

Wind Energy Report

Box 14 - 104 S. Village Avenue

Rockville Centre, NY 11571 
No. of Copies

Copies

FOREIGN

Le if Kristensen

Department of Physics

Risø National Laboratory

4000 Roskilde

DENMARK

Per Lundsager

Ris $\varnothing$ National Laboratory

P.0. Box 49

DK-4000 Roskilde

DENMARK

Dr. M. B. Anderson

Sir Robert McAlpine \& Sons, Ltd.

40 Bernard Street

London WC1N 1 LG

ENGLAND

Dr. D. Wilson

Cavendish Laboratory

Madingley Road

Cambridge CB3 OHE

ENGLAND

H. H. Rosenbrock

The University of Manchester

Institute of Science and Technology

P.O. Box No. 88

Manchester M60 100

ENGLAND

D. Lindley

Taylor Woodrow Construction, Ltd.

Taywood House

345 Ruislip Road

Southall

Middlesex UBI 2QQX

ENGLAND

Dr. Werner Dub

Forschungsprojekt Windenergie

Universitatsstrasse 31

D-8400 Regensburg

GERMANY, FRG
No. of

Copies

Dr. Neil Cherry

Lincoln College

Canterbury

NEW ZEALAND

ONSITE

DOE Richland Operations Office

H. E. Ransom/D. R. Segna

31 Pacific Northwest Laboratory

J. W. Buck

J. R. Connel1

D. W. Dragnich

C. E. Elderkin

D. L. Elliott

P. C. Hays

S. K. Heflick

B. D. Holst

A. H. Miller

V. R. Morris

E. L. Owczarski

D. C. Powell (5)

D. S. Renne

H. L. Wegley

L. L. Wendel 1

Publishing Coordination (2)

Technical Information (5)

WCPE Program Office (5) 


\section{-}

